\title{
In vitro comprehensive analysis of VA692 a new chemical entity for the treatment of osteoarthritis
}

Sara Cheleschi ${ }^{1}$, Valentina Calamia ${ }^{2}$, Mercedes Fernandez-Moreno ${ }^{2,3}$, Mariangela Biava ${ }^{4}$, Antonio Giordani ${ }^{5}$, Maurizio Anzini ${ }^{6}$, Francisco Blanco ${ }^{2}$ and Antonella Fioravanti ${ }^{1, \$}$.

${ }^{1}$ Department of Medicine, Surgery and Neuroscience, Rheumatology Unit, University of Siena, Policlinico Le Scotte, Viale Bracci 1, 53100 Siena, Italy

${ }^{2}$ Servicio de Reumatología, Instituto de investigación Biomedicas A Coruña (INIBIC). Hospital Universitario A Coruña (CHAUC) Sergas. Universidade da Coruña, A Coruña, Spain

${ }^{3}$ Centro de investigación biomédica en Red, Bioingeniería, Biomateriales y Nanomedicina (CIBER-BBN) Madrid Spain.

${ }^{4}$ Department of Chemistry and Drug Technologies, University "La Sapienza" Rome, P.le Aldo Moro, 5, 00185, Rome, Italy

${ }^{5}$ Rottapharm Biotech, Via Valosa di Sopra 6, 20126 Monza, Italy

${ }^{6}$ Department of Biotechnology, Chemistry and Pharmacy, University of Siena, Via A. Moro, 2 - 53100 Siena, Italy

${ }^{\$}$ Corresponding author:

Dr. Antonella Fioravanti

Rheumatology Unit,

Department of Medicine, Surgery and Neurosciences, University of Siena, Italy

Viale Bracci 1, 53100 Siena, Italy

Phone: ++390577 233345

Fax: ++39057740450

E-mail:fioravanti7@virgilio.it

Running title: The effect of VA692 in an in vitro study on human chondrocyte cultures 


\section{Abstract}

Selective cyclooxigenase (COX)-2 inhibitors were developed to prevent Traditional Non-Steroidal Anti-Inflammatory DrugS ( $t$ NSAIDs) gastro-intestinal adverse effects. VA692, a recently disclosed selective COX-2 inhibitor, structurally related to well-known marketed coxibs, showed antiinflammatory, and anti-nociceptive properties.

The aim of this study was to analyze the anti-inflammatory effect of VA692, in comparison with celecoxib. For this purpose we evaluated pro-inflammatory cytokines and anti-oxidant enzymes gene expression, apoptosis and ROS production, and $\mathrm{PGE}_{2}$ release in chondrocytes (both primary cultures and immortalized cell line T/C-28a2) treated with the two drugs. Furthermore, a proteomic analysis has been performed in T/C-28a2 cell line to evaluate modifications in their proteomic profile following drug treatment in presence of IL-1 $\beta$.

Our results demonstrated the anti-inflammatory effect of the novel synthesized VA692, and confirmed those of celecoxib, in counteracting the stimulus of IL-1 $\beta$ in both osteoarthritic (OA) chondrocytes and T/C-28a 2 cell line. Furthermore, the data underlined the possible anti-apoptotic and anti-oxidant role of VA692, implying its regulation in superoxide anion production as indicated by the modulation of anti-oxidant enzymes.

The proteomic analysis provides new information about the effect of VA692 on human T/C-28a2 intracellular proteome, demonstrating the usefulness of this approach in the identification and quantifications of several proteins. Modulation of some proteins such as Hsp90 and SOD by VA692 could explain its role in the therapeutic approach of OA.

Based on our results, we can affirm that VA692 has more beneficial effect compared with celecoxib particularly regarding the modulation of oxidant/anti-oxidant system and proteome profile of human articular chondrocytes.

Keywords: Selective cyclooxigenase 2 inhibitors, VA692, Osteoarthritis, chondrocyte cultures, intracellular proteome 


\section{Introduction}

Osteoarthritis (OA) is the most common rheumatic disease affecting middle aged and older people worldwide and it is the main cause of disability and impairment in adults [1]. The disorder is characterized by progressive destruction of cartilage and subochondral bone remodeling accompanied by synovial inflammation and loss of normal joint function [2].

The international guidelines for the treatment of OA include non-pharmacological and pharmacological approaches. The pharmacological management actually available is represented by acetaminophen, traditional non-steroidal anti-inflammatory drugs ( $t$ NSAIDs), analgesics, opioids and duloxetine (a serotonin and norepinephrine reuptake inhibitor with central nervous activity), which provide only symptomatic relief [3,4].

The clinical efficacy of $t$ NSAIDs is related to their ability in modulating pain and inflammation impairing prostaglandin $\mathrm{E} 2\left(\mathrm{PGE}_{2}\right)$ release by means of the inhibition of cyclooxygenase $2(\mathrm{COX}-$ 2) activity [5]. However, gastrointestinal and renal adverse effects of $t$ NSAIDs due to their inhibition of the constitutive cytoprotective COX-1 is well established [6,7], even if this concept was recently challenged by the detection of constitutive COX-2 activity in several tissues and organs, including the kidney and brain [8].

In addition, the possible negative effect of $t$ NSAIDs on cartilage metabolism, in particular in long term treatment, was documented [5]. However, data about their effects on articular cartilage are not consistent; in fact, some reports evidence the involvement of these drugs in cartilage destruction, while, in other studies, their chondroprotective action was observed [9-11].

Selective COX-2 inhibitors belongs to the class of diaryl heterocycles compounds, also referred to as coxibs [12]. These drugs specifically act on COX-2, with similar efficacy and less toxicity $[13,14]$, and have been developed to prevent common adverse effect associated to $t$ NSAIDs. Along with beneficial anti-inflammatory activity of celecoxib, the prototype of coxibs, many in vitro studies reported its positive effect on cartilage damage during OA [15-17]. Unfortunately, an increased risk for cardiovascular events has been associated with chronic use of $t$ NSAIDs and 
coxibs $[18,19]$. The discovery of certain variability in individual reactions to these drugs, mainly due to patient's genetic background [20] and the need of potentially safer drugs for the successful management of $\mathrm{OA}$, promoted strategies of design and synthesis of new class of pyrrole-containing antiflogistic/analgesics agents as selective COX-2 inhibitors, structurally related to the main coxibs $[21,22]$.

Within a large program aimed at the discovery of new anti-inflammatory agents based on the 1,5diarylpyrrole scaffold, a series of substituted 1,5-diarylpyrrole-3-alkoxyethyl ethers endowed with a relevant anti-inflammatory and anti-nociceptive properties was disclosed [23]. The manipulation of 3-alkoxyethyl chain of above-cited compounds allowed some of us to obtain 1,5-diarylpyrrole-3nitrooxyethyl derivative VA694, a hitherto unknown COX-inhibiting nitric oxide (NO) donor offering an improved safety profile having a dual mechanism of action involving COX-2 inhibition and NO release (Figure 1). This molecule resulted to be very active, being endowed with high selective COX-2 inhibitory properties, highlighting its anti-inflammatory and antinociceptive activity [24], associated with chondroprotective effects when tested on human chondrocytes [25]. Along with VA694 it appeared interesting to deepen the pharmacological behaviour of its metabolite, resulting from the metabolic conversion of nitrooxyalkyl ether VA694 into the corresponding hydroxyethyl derivative VA692 which, after NO release, still retained a very promising selective COX-2 inhibition, showing appreciable anti-inflammatory and anti-nociceptive activity in animal model of inflammation [24]. On the basis of these findings VA692, underwent biological assays performed on bovine articular cartilage, showing chondroprotective effects being able to inhibit glycosaminoglycans release induced by Interleukin (IL)-1 $\beta$ [24].

So, the aim of this study was to analyze the anti-inflammatory effect of the novel selective COX-2 inhibitor, VA692, in comparison with celecoxib, as the reference compound, in both human chondrocyte cell line T/C-28a2 and in primary cultures of human articular OA chondrocytes (HAC). All the experiments were performed in the presence of IL-1 $\beta$. By means of the isobaric tags for relative and absolute quantitation (iTRAQ) methodology, our goal was to identify the profile of 
proteins produced by our chondrocyte cultures, and to quantitatively analyze the different expressed profiles after the treatment with the drugs of interest in presence of IL-1 $\beta$. This allows us to better understand and characterize the possible mechanism of action of celecoxib and VA692.

\section{Material and Methods}

\subsection{Culture of chondrocytes}

Human T/C-28a2, kindly provided by Glodring laboratory, was derived from human juvenile costal cartilage generated through a transfection with retroviral vector pZipNeoSV (X) containing the SV40 large T antigen as previously described [26]. These immortalized human chondrocytes can be manipulated in culture, displaying cartilage-specific modulation by inflammatory mediators, so they can be used as a model for studying normal and pathological mechanisms, allowing investigations in a largely unlimited and standardized way [26].

Human articular cartilage was obtained from the femoral heads of five OA patients undergoing hip replacement surgery [27,28] in the Orthopaedic Department at University Hospital of A Coruña, Spain and at University Hospital of Siena, Italy. The study was approved by the Ethic Committee of Clinical Investigation of Galicia and by the Ethics Committee of the Azienda Ospedaliera Universitaria Senese. The sex distribution of patients was two males and three females with a mean age of 68 years (range 66-72).

The chondrocytes were isolated after surgery. Briefly, cartilage sections were aseptically removed from each donor and enzymatically digested with trypsin (Sigma-Aldrich) for 15 minutes (min) at $37^{\circ} \mathrm{C}$ and then with type IV collagenase (Sigma-Aldrich) for $12-16$ hours (h) at $37^{\circ} \mathrm{C}$. Chondrocytes were recovered, seeded into $10-\mathrm{cm}$ diameter tissue culture plates and maintained in a $5 \% \mathrm{CO}_{2}$ and $90 \%$ humidified atmosphere at $37^{\circ} \mathrm{C}$ until $80 \%$ confluence was reached. Cells were grown in Dulbeccós Modified Eagle Medium (DMEM) (Gibco), containing 10\% Fetal Bovine Serum (FBS)

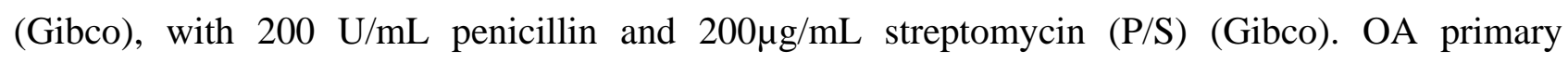
chondrocytes were used at first passage in all the experiments thus ensuring the preservation of their phenotypic stability. 


\subsection{Pharmacological treatment of the cell cultures}

The effects of our compound VA692 and celecoxib (kindly supplied by Rottapharm Biotech, Italy) were analyzed in the presence of IL-1 $\beta(5 \mathrm{ng} / \mathrm{ml})$ (Sigma) after $2 \mathrm{~h}$ of pre-treatment with the compounds. All the experiments were carried out during $48 \mathrm{~h}$ after cells treatments in DMEM with $0 \%$ FBS.

The drugs were dissolved in dimethyl sulfoxide (DMSO) (Sigma) and then further diluted in the culture medium to obtain the final concentration required. The concentration of DMSO in the medium during the treatment did not exceed $0.1 \%$ neither affecting cell growth nor its well known anti-oxidant activity [29].

\subsection{Experimental procedures}

\subsubsection{RNA isolation and gene expression}

Total RNA from cells was extracted using Trizol® Reagent (Thermo Fisher Scientific) following the manufacture's procedures. Afterwards, $1 \mu \mathrm{g}$ of total RNA was reverse transcribed using NZY First-Strand cDNA Kit (NZY Tech Genes and Enzymes, Portugal) according to manufacturer's instructions.

Quantitative real-time PCR (qRT-PCR) reactions were performed in LightCycler 480 II instrument (Roche Molecular Biochemicals) using TaqMan Universal Master Mix (Applied Biosystems) Analysis of the results was carried out using Qbase+ version 2.5 software (Biogazelle, Gent, Belgium) using $\Delta \Delta \mathrm{Ct}$ method. Normalization was carried out considering as reference housekeeping gene ribosomal protein L13a (RPL13A). This gene was chosen by software geNorm version 3.5 (Primer design, Southampton University's School of Medicine, United Kingdom), an algorithm able to evaluate the most stable housekeeping gene derived from a group of tested candidate reference genes. The software determines the gene expression stability measure for a reference gene calculating the average pairwise variation of that gene in comparison to all other tested genes. Stepwise exclusion of the gene with the highest stability measure value allows to calculate the tested genes according to their expression stability [30]. Sequence of primers and 
probes are listed in Table 1.

\subsection{2 $P G E_{2}$ release}

$\mathrm{PGE}_{2}$ levels were evaluated in the conditioned media and determined through competitive $\mathrm{PGE}_{2}$ EIA -Monoclonal kit from Cayman Chemical Co. (Ann Arbor, MI, USA) according to the supplier's instructions. Sensitivity of the assay was $15 \mathrm{pg} / \mathrm{ml}$. Inter-assay and Intra-assay coefficients of variation were $12.4-35 \%$ and $4.2-30.4 \%$, respectively.

\subsubsection{Detection of apoptotic cells}

Detection of apoptotic cells were developed using Annexin V-FITC and propidium iodide (Immunostep). T/C-28a2 cell line and OA chondrocyte cultures were plated in 12 -well plates $\left(8 \times 10^{4}\right.$ cells per well) during 24 hours in DMEM with FBS 10\%. Then, the medium was discarded and the cells were cultured in DMEM with FBS $0.5 \%$ normally used for the treatment $(n=3)$. Afterwards, the cells were washed and harvested with trypsin, collected into cytometry tubes and centrifuged for 10 minutes at $1500 \mathrm{rpm}$. The supernatant was discarded and the pellet resuspended in $1 \mathrm{X}$ annexin binding buffer followed by $5 \mu \mathrm{l}$ of Annexin V-FITC and $5 \mu \mathrm{l}$ of propidium iodide (PI) addition to each cell suspension and incubated at room temperature for $15 \mathrm{~min}$ in darkness. After incubation, $400 \mu \mathrm{l}$ of $1 \mathrm{x}$ Annexin-binding buffer was added prior to flow cytometry analysis. A total of $1 \times 10^{4}$ cells per assay were measured. Data were analyzed with Cell Quest software (Becton Dickinson). The evaluation of apoptosis was performed considering staining cells simultaneously with Annexin V-FITC and PI, allowing the discrimination of intact cells (Annexin V-FITC and PI negative), early apoptotic state (Annexin V-FITC positive and PI negative) and late apoptosis state (Annexin VFITC and PI positives).

Results were expressed as percentage of positive cells to each dye (total apoptosis) and represented the mean of three independent experiments (mean \pm standard deviation (SD)). 


\subsubsection{Mitochondrial ROS production}

To evaluate mitochondrial superoxide anion $\left(\mathrm{O}_{2}^{-}\right)$production the cells were incubated in Hank's Balanced Salt Solution (HBSS) (Sigma) with $5 \mu \mathrm{M}$ of MitoSOX ${ }^{\mathrm{TM}}$ Red (Thermo Fisher Scientific), during $15 \mathrm{~min}$ at $37^{\circ} \mathrm{C}$ in darkness. Besides, cells were resuspended in saline solution prior to be analyzed by flow cytometry. A total of $1 \times 10^{4}$ cells per assay were measured by flow cytometry and data were analyzed with CellQuest software (Becton Dickinson). Results were collected as median of fluorescence $(\mathrm{AU})$ and represented the mean of three independent experiments (mean $\pm \mathrm{SD})$.

\section{Total protein extraction and western blot analysis}

$3 \times 10^{5}$ T/C-28a2 cells were plated onto 6-multi plates during 24 hours in DMEM without phenol red (Gibco, Thermo Fisher Scientific) with FBS 10\%. Then, the medium was discarded, and the cells were cultured in DMEM with FBS $0.5 \%$ normally used for the treatment. After the treatment, the cells were lysed using $100 \mu \mathrm{l}$ of lysis buffer $[0.2 \mathrm{M}$ Tris- $\mathrm{HCl} \mathrm{pH} 6.8$, sodium dodecyl sulphate (SDS) 2\%, Glycerol 20\%] with additional inhibitors to prevent degradation of the samples (PMSF $0.1 \mathrm{M}$ and protease inhibitor cocktail (Sigma)). The concentration, purity and integrity of proteins

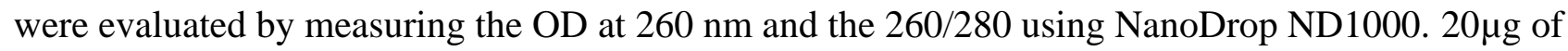
protein for each sample were loaded and resolved using 10\% SDS-polyacrylamide electrophoresis gel (SDS-PAGE) (Power Pac TM HC, Bio-Rad). Proteins were then transferred to nitrocellulose membrane (Trans-Blot SD, BioRad) and, after blocking, the membrane was incubated with the purified mouse monoclonal antibody for SOD2 detection (BD Biosciences Transduction Laboratories TM) (1:1000). Finally, immunoreactive bands were detected by chemiluminescence using the appropriated horseradish peroxidase (HRP) conjugate secondary antibodies and enhanced chemiluminescence detection reagent (Luminata ${ }^{\mathrm{TM}}$ Western HRP Chemiluminescence Substrates) (Millipore). Images of the bands were digitized using LAS-3000 Image Reader (Bio-Rad) and quantitative changes in band intensities were analyzed by Image Quant 5.2 software (GE Healthcare). To assure the evaluation of an equal amounts of the total proteins, membrane was also 
hybridized with monoclonal human anti- $\beta$-tubulin antibody, used as control. Results were normalized with the loading control $\beta$-tubulin.

\subsubsection{Protein digestion and iTRAQ labeling}

The cells were collected, lysed with urea $6 \mathrm{M}$ and thiourea $2 \mathrm{M}$ and cleaned up by acetone precipitation. Protein pellets were dried at air and then resuspended in $30 \mu$ l of Dissolution Buffer (0.5 M triethylammonium bicarbonate at $\mathrm{pH}$ 8.5) (AB Sciex, Foster City, CA, USA). Protein concentration was determined by using NanoDrop ND1000 (Thermo Scientific). Then, $50 \mu \mathrm{g}$ of proteins from each condition were reduced, alkylated, and digested with trypsin. Then iTRAQ labeling was performed according to the supplier's instructions (ABSciex, Foster City, CA, USA).

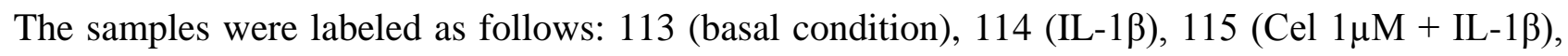
$116(\mathrm{VA692} 1 \mu \mathrm{M}+\mathrm{IL}-1 \beta), 117$ (basal condition), 118 (IL-1 $\beta), 119(\mathrm{Cel} 1 \mu \mathrm{M}+\mathrm{IL}-1 \beta), 121$ (VA692 1 $\mu \mathrm{M}+\mathrm{IL}-1 \beta)$. iTRAQ-labeled peptides were mixed and desalted using reversed phase columns (Pierce C18 Spin Columns, Thermo Fisher Scientific, Rockford, IL, USA) prior to liquid chromatography coupled to mass spectrometry (LC-MS) analysis.

\subsubsection{Liquid Chromatography (LC)}

The peptides mixture was separated by off-line reversed phase (RP) - $\mathrm{LC}$ at basic $\mathrm{pH}(\mathrm{pH} 10)$ to lower its complexity. Labeled peptides were resuspended in $150 \mu \mathrm{L}$ of buffer A $(10 \mathrm{mM}$ ammonium hydroxide, $5 \%$ acetonitrile), $140 \mu \mathrm{L}$ were injected into an HP 1200 system (Agilent Technologies, Santa Clara, CA, USA) and the separation was performed on a C18 reversed-phase column (Zorbax extend C18, $100 \times 2.1 \mathrm{~mm} \mathrm{id,} 3.5 \mu \mathrm{m}, 300 \AA$; Agilent), at a flow rate of $0.2 \mathrm{~mL} / \mathrm{min}$. The chromatogram was detected using a UV detector at $214 \mathrm{~nm}$. Several fractions were pooled postcollection (FC203B fraction collector, Gilson, Middleton, WI, USA) based on the peak intensity of the UV trace, yielding a total of 16 samples per LC run. Each fraction was dried in a vacuum concentrator and stored at $-20^{\circ} \mathrm{C}$ for the next step of analysis. For a second separation, the dried peptide fractions were dissolved in $0.1 \%$ trifluoroacetic acid (TFA) and $2 \%$ acetonitrile. Then, $5 \mu \mathrm{L}$ 
of the sample were injected into a capillary trap column $(0.5 \times 2 \mathrm{~mm}$, Michrom Bioresources, Auburn, CA, USA) at a flow rate of $15 \mu \mathrm{L} / \mathrm{min}$. Peptides were desalted for 10 minutes and loaded in a C18 column (Integrafit C18, Proteopep II, $75 \mu \mathrm{m}$ id, $10.2 \mathrm{~cm}, 5 \mu \mathrm{m}, 300 \AA$; New Objective), at a constant flow rate of $350 \mathrm{nl} / \mathrm{min}$, to carry out the separation using linearly increasing concentration of acetonitrile in buffer B. The RP fractions were collected and mixed with matrix a-cyano-4hydroxycinnamic acid (Sigma-Aldrich) at $3 \mathrm{mg} / \mathrm{mL}$ in $0.1 \%$ TFA in $70 \%$ acetonitrile at a flow rate of $1.2 \mu \mathrm{L} / \mathrm{min}$, using the Sun Collect MALDI Spotter/Micro Collector (SunChrom Wissenschaftliche Gerate GmbH, Germany). Fractions, collected each 15 seconds, were then spotted onto a MALDI plate for MS analysis.

\subsubsection{MS/MS analysis}

Data acquisition was accomplished in a positive ion mode using a 4800 analyzer equipped with TOF/TOF ion optics (ABSciex) and 4000 Series Explorer software version 3.5.1 (ABSciex). MS spectra from m/z 800-4000 were acquired for each fraction using 1500 laser shots processed with internal calibration. After screening of LC-MALDI sample positions in MS positive reflector mode, the fragmentation of automatically selected precursors was performed at a collision energy of $1 \mathrm{kV}$ with CID gas (air). Up to 25 of the most intense ion signals per spot position with signal/noise ratio (S/N) above 80 were selected as precursors for MS/MS acquisition. The number of shots was 2000 for MS/MS, the laser intensity was set to 4700. A second MS/MS was acquired excluding the precursors selected in the previous MS/MS run. Precursors with S/N>30 were selected to identify proteins that were not identified in the previous run.

\subsubsection{MS data analysis}

Protein identification was carried out by Protein Pilot ${ }^{\mathrm{TM}}$ software version 4.5 (ABSciex). The Paragon algorithm in the software needed as the default search program with trypsin as the digestion agent and MMTS as a fixed modification of cysteine. Biological modifications were programmed in the algorithm. Each MS/MS spectrum was researched in the Uniprot/Swissprot 
database for Homo sapiens. The identity of the protein from the analyzed peptide was confirmed and the ratio of the peak are of iTRAQ reporter ions were used to compare the abundance of the protein found in the sample. Only proteins identified with at least $95 \%$ of confidence, or a Prot Score (protein confidence measure) of at least 1.3 were reported. Data were normalized for loading

error by bias and the background correction was calculated through Pro Group ${ }^{\mathrm{TM}}$ algorithm (ABSciex). To determine the cut-off value for significant fold changes, coefficient of variation and cumulative frequency were calculated for the common proteins employing the $\mathrm{R}$ statistical package. The results obtained from Protein Pilot were exported to Microsoft Excel for other analyses.

\subsubsection{Statistical analysis}

Proteomics data were analyzed employing normalization tools and statistical package from ProteinPilot. The results obtained were exported to Microsoft Excel for further analyses. Three independent experiments were performed and the results were expressed as the mean $\pm \mathrm{SD}$ of triplicate values for each experiment. Data normal distribution was confirmed by Shapiro-Wilk, D’Agostino \& Pearson e Kolmogorov-Smirnov tests. Quantitative real-time PCR data were evaluated by Kruskal-Wallis test with Dunn's multiple comparison test using $2^{-\Delta \Delta C}{ }_{T}$ values for each sample. Flow cytometry results were analyzed by ANOVA with Bonferroni post-hoc test. All analyses were performed using the SAS System (SAS Institute Inc., Cary, NC, USA) and GraphPad Prism 6.1. A significant effect was indicated by a p-value $<0.05$.

\section{Results}

\subsection{Anti-inflammatory capacity of celecoxib and VA692}

The chondrocytes (T/C28-a2 and HAC) were stimulated with IL-1 $\beta$ to induce an inflammatory response, this status was confirmed by a significant up-regulation expression level of all genes analysed and a significant $\mathrm{PGE}_{2}$ release levels in comparison with the basal condition.

A significantly inhibition of the gene expression of the inflammatory indicators evaluated (COX-2, IL-1 $\beta$, IL-6 and IL-8) was observed with celecoxib or with the new compound VA692 at the 
concentration of $1 \mu \mathrm{M}$ (Figure 2A,B). In the case of VA692 the inhibition of 4 gene expression were obtained also at low concentrations evaluated (data not shown) and this results was more significant in the case of chondrocytes from OA patients than in the chondrocytes from cell line.

Another analysis developed to evaluate the possible anti-inflammatory response in the chondrocytes after drug treatment was the detection of $\mathrm{PGE}_{2}$ release. Celecoxib significantly inhibited $\mathrm{PGE}_{2}$ release induced by IL-1 $\beta$ in both cell types (Figure 2C). The new compound VA692 showed the same effect over the both type of cells analyzed, reflecting a significant decreased in the $\mathrm{PGE}_{2}$ levels, up to basal concentration (Figure 2C).

\subsection{The effect of the compounds over the oxidant/anti-oxidant system and apoptosis detection}

The assessment of mitochondrial ROS production, estimated by the measurement of anion superoxide by flow cytometry, showed that IL-1 $\beta$ increased significant the levels of $\mathrm{O}_{2}^{-}$in comparison with basal condition. The cell treatment with either celecoxib or VA692 at $1 \mu \mathrm{M}$ had the capacity to counteract the negative effect of IL-1 $\beta$ in T/C-28a2 cell line and in HACs reducing the levels of $\mathrm{O}_{2}^{-}$up to basal condition (Figure 3A).

As shown in Figure 3B and $\mathrm{C}$, the gene expression of two detoxification enzymes (SOD-2 and CAT) was analysed after stimulation with IL-1 $\beta$ and treatment with celecoxib and VA962. Il-1 $\beta$ provoked a strong increase of mRNA levels of both enzymes in both cell types. After pharmacological treatments, a statistical significant decrease was observed in comparison with Il-1 $\beta$ condition in chondrocytes from cell line and primary culture. The reducing effect was similar for both drugs in HACs while in T/C-28a2 was higher for the new compound VA692 (Figure 3B,C). Western blot was developed to complete the study of drugs effect over the mitochondrial ROS production (Figure3D). The densitometry quantification showed significantly higher SOD-2 protein levels after stimulation with IL-1 $\beta$, in comparison to basal conditions. A higher increase of SOD-2 protein levels was observed after treatment with celecoxib, and VA692. The percentage of apoptotic cells after pharmacological treatment was also evaluated. As shown in figure $3 \mathrm{E}$, flow cytometry data showed that the stimulation with IL- $1 \beta$ significantly increased the ratio of apoptosis (the ratio 
of apoptosis was referenced to basal condition) in T/C-28a2 cell line (130\% increase) and in HACs (50\% increase). The treatment with celecoxib or VA692 was able to restore the ratio of apoptosis up to basal condition in T/C-28A2 and in less extent in HACs, being in this case statistically significant only for celecoxib.

\subsection{Proteomic profiling of celecoxib or VA692 IL-1 $\beta$-treated cell cultures}

A total of 797 proteins have been identified with at least two distinct peptides (95\% of confidence) and a protein pilot total score $\geq 2$ after combining the results from all the experiments (false discovery rate kept at $1 \%$ ) (Supplementary Table S1). As expected, the most abundant proteins in all the conditions were cytoskeletal proteins. In particular, intermediate filament protein vimentin (VIME), filamins (FLNA, FLNB, FLNC), alpha actinin- (ACTN1), or proteins involved in calcium metabolism such as calreticulin (CALR) and calumenin (CALU) have been identified. Proteins involved in synthesis and maturation of ribosomes, such as nucleophosmin (NPM) and nucleolin (NUCL), as well as in osteoablast differentiation, clathrin heavy chain 1 (CLH1) and fatty acid synthase (FASN), were also identified. A gene ontology (GO) enrichment analysis was performed on this set of proteins and the Pike tool was used to assign the involved biological processes and the cellular compartment distribution of the identified proteins (35). Bioinformatic analysis demonstrated the involvement of these proteins in several cellular (32\%) and metabolic (26\%) processes, in particular regulating cell cycle (cytoskeletal proteins) and cell communication (signal transduction molecules) (Figure 4A). As described in figure 4B, 95\% of the identified proteins were associated to the intracellular compartment; $46 \%$ of them were located inside the cytoplasm, $15 \%$ inside the cytoskeleton, $13 \%$ inside the nucleous, or located in other subcellular organelles such as endoplasmic reticulum (11\%) and mitochondrion (6\%).

Proteomics analysis by iTRAQ labelling also enabled the relative quantification of the identified proteins. The iTRAQ ratios were calculated using the Protein Plot software, and subsequently the cut off value for significant fold changes was established at $\geq 1.5$ (or $\leq 0.66$ ) using statistic tools from $\mathrm{R}$ package. Afterwards, we found 34 proteins significantly modulated $(\mathrm{p} \leq 0.05)$ in IL-1 $\beta$ 
stimulated T/C-28a2 cells in comparison to basal conditions: 26 were up-regulated and 8 were down-regulated (Table 2). Only 7 proteins were significantly modulated by celecoxib treatment in comparison to basal conditions, 5 were up-regulated while 2 down-regulated (Table 3); on the other hand, VA692 was able to modulate, in a significant manner, 123 proteins, 70 of them were increased and 53 were decreased (Table 4). The Venn diagram represents the overlap of proteins altered in T/C-28a2 VA692 in presence of IL-1 $\beta$ and the IL-1 $\beta$ tested alone, highlighting the characteristic protein profile induced by each treatment; only 22 proteins were commonly modulated by the two treatments, indicating that 101 proteins were regulated by the only effect of VA692 in a specific manner (Figure 4C). Among them, proteins with structural function, chaperone and glycolitic enzymes resulted decreased after pharmacological treatment. In addition, STRING database was searched for protein interaction analyses to evaluate the effect of VA692 in combination with IL-1 $\beta$. Figure $5 \mathrm{~A}$ showed the interaction of the 53 down-regulated proteins with each other to constitute a network; some of them are involved in osteoblast differentiation (Figure 5B). Figure $5 \mathrm{C}$ depicting the interaction of the 70 up-regulated proteins with each other to constitute a network; some of them are involved in protein translation (Figure 5D).

\section{Discussion}

The present study examines the in vitro anti-inflammatory effects of a new selective COX-2 inhibitor, VA692, along with celecoxib as the reference compound. T/C-28a2 cell line was employed to perform all the preliminary analysis with different concentration of both drugs. Then, the optimal conditions were tested in primary chondrocytes to confirm the results. The concentrations of the drugs tested in our experiments were close to those found in vivo and comparable with the concentrations tested by other authors [15,23]. All the experiments were performed in presence of the cytokine IL-1 $\beta$, generally used in in vitro models to mimic the circumstances driving to in vivo cartilage degradation $[31,32]$.

Previous results from in vitro tests have been performed to evaluate the inhibitory potency and 
selectivity of the title compounds, and reported very encouraging COX-2 inhibitory activity of VA692 ( $\mathrm{IC}_{50}$ of $\left.0.089 \mu \mathrm{M}\right)$ (celecoxib, $\mathrm{IC}_{50}$ of $\left.0.089 \mu \mathrm{M}\right)$ [23]. Cosidering its very encouraging inhibitory activity, compound VA692 was submitted to additional pharmacological evaluations to assess its in vivo anti-inflammatory and anti-nociceptive activities. Firstly, an analysis on a chemical murine model of visceral pain, induced by an intraperitoneal injection of acetic acid, was performed; the evaluation of the number of abdominal constrictions induced by acetic acid proved the analgesic properties of VA692 compared to celecoxib [23]. Moreover, the effect of VA692 on pain threshold alteration and oedema reduction was observed, by the same authors, in rats injected with carrageenan; the compound was able to block the painful stimulus showing a good activity against carrageenan-induced hyperalgesia [23]. Finally, the efficacy of VA692 was also determined in a rat OA model induced by intra-articular knee injection of monoiodoacetate (MIA), able to induce chondrocytes necrosis, decrease in cartilage thickness and osteolysis. Repeated treatment with VA692 prevented monoiodoacetate hyperalgesia [23].

On the basis of these preliminary results, in the present study we tested the effect of VA692 also in human chondrocyte cultures in order to evaluate its possible modulation of cell metabolism.

The results obtained in HAC stimulated with IL-1 $\beta$, support the data from literature reporting a significant increase of IL-1 $\beta$, IL-6, IL-8, as well as a large amount of PGE $_{2}$ production, which is reasonable to be related to the increase of COX-2 gene expression [33]. On the other hand, this is the first study showing an up-regulation of these pro-inflammatory cytokines expression levels in T/C-28a2 cell line. de Boer et al [34] evaluated the effect of celecoxib in vivo in patients with knee OA. The authors observed the reduction in $\mathrm{PGE}_{2}$ levels in treated group compared to controls, indicating the ability of this compound in inhibiting COX-2 effect. In addition, in vitro and in vivo studies (in animal models of OA) demonstrated the anti-inflammatory effect of celecoxib, with respect to $t$ NSAIDs, in counteracting the $\mathrm{COX}-2$ and $\mathrm{PGE}_{2}$ production after the pro-inflammatory stimulus of IL- $1 \beta$ and TNF- $\alpha[16,35,36]$. According to these studies, our data on primary cultures confirm the anti-inflammatory effect of celecoxib in reducing the expression of COX-2 and the 
release of $\mathrm{PGE}_{2}$ induced by IL-1 $\beta$. In addition, the drug also caused a down-regulation in IL-6 and IL-8 expression levels, confirming the data by Sanchez et al. [37]. Furthermore, we demonstrated that the novel compound VA692 had a similar anti-inflammatory effect to celecoxib, showing a better modulation of IL-6, IL-8 and $\mathrm{PGE}_{2}$ in cell line model and in primary OA chondrocytes.

Accumulating evidence indicates chondrocyte apoptosis as another important factor involved in the pathogenesis of OA. Apoptosis analysis performed in our research appeared in agreement with previous studies [38,39] showing a trend to increase of apoptosis percentage in OA chondrocytes stimulated with IL-1 $\beta$, even if not significant, principally attributed to experimental variability and at the low number of available samples; with regard to T/C-28a2 cell line, a significant increase of apoptotis in IL-1 $\beta$-stimulated cells was observed. Our treatment demonstrated the ability of celecoxib in reducing, in a significant manner, the apoptosis ratio in human T/C-28a2 cell line after the negative stimulus of IL-1 $\beta$, showing a trend also in counteracting the ratio of apoptosis in primary OA chondrocytes cultures, as previously described [40]. More interestingly, we underlined for the first time the anti-apoptotic effect of the new compound VA692, able to restore cell viability after stimulation with IL-1 $\beta$ in T/C-28a2 cell line.

Under normal conditions, the production of endogenous ROS are balanced by the antioxidant defence system. In pathological circumstances as OA, when the cellular antioxidant ability is not sufficient to detoxify ROS, the oxidative radicals accumulation affects cellular membranes, nucleic acids and extracellular matrix components [41]. Chondrocytes from OA cartilage have significantly more ROS-induced DNA damage than in normal cartilage, mediated by IL-1 $\beta$ effect with an increase in their mitochondrial superoxide levels [42]. Our data appear in agreement with the current literature showing a trend of increase in mitochondrial superoxide anion production both in T/C-28a2 cell line and in OA chondrocytes cultures stimulated by IL-1 $\beta$.

A limited number of in vivo and in vitro studies have been performed regarding the effects of coxibs on oxidant/antioxidant activities $[16,42,43]$, in particular with a lack of evidence about their effects on chondrocytes. An in vivo study of Ozgocmen et al [43] documented the effect of celecoxib in 
reducing NO levels in patients with knee OA; moreover, the inhibition of NO production, after IL$1 \beta$ stimulus, by celecoxib was observed in chondrocytes of ligament-damaged OA rat joints [16]. Our results seem to support this evidence reporting the inhibitory role of celecoxib in oxidant system, showing its effect in reducing the superoxide anion production in T/C-28a2 cell line. In addition, a more evident effect was observed after the treatment with the new compound VA692 in both cell culture models showing its ability to counteract the mitochondrial $\mathrm{O}_{2}^{-}$production induced by IL-1 $\beta$. We also observed a significant increase of both SOD-2 and CAT mRNA expression levels in T/C-28a2 cell line and in OA chondrocyte following incubation with IL-1ß. This led us to speculate about the raised levels of these detoxificant factors could be related to the increase of their activity as a consequence of increased ROS production after the cell incubation in presence of proinflammatory cytokines essentials in the development of OA processes.

Cimen et al [44] studied the effect of celecoxib, ibuprofen and meloxicam on free radical metabolism of erythrocytes in OA patients, reporting a significant decrease in SOD activity in patients treated with the drugs. More recently, it has been compared the effect, on free radical metabolism, of tenoxicam and celecoxib in serum levels of OA patients. Patients treated with celecoxib decreased their nitrite levels, while no changes in SOD activity were observed compared to baseline [43]. Our report confirm the effecacy of celecoxib in modulating SOD-2 and CAT and, more interestingly, showed the ability of the new compound VA692 in reducing antioxidant enzymes mRNA expression levels, in T/C-28a2 cell line and in OA chondrocytes cultures after stimulation with IL-1 $\beta$. To summarize, we showed for the first time the role of VA692 in redox balance, demonstrating its effect in the reduction of both superoxide anion production and antioxidant enzymes.

Surprisingly, conversely to our SOD-2 mRNA result, its protein levels appeared increased after the treatment with the new molecule VA692 following our analysis carried out at western blot test in T/C-28a2 cell line. There is no evidence about an increase of its protein levels afterwards a drug treatment in this type of cell line. However, a recent in vitro pharmacoproteomic study performed in 
OA chondrocyte cultures appeared in agreement with our data reporting higher SOD-2 protein levels in that cells after treatment with chondroitin sulfate and IL-1 $\beta$ [45]. These obtained data might stimulate to deeper investigate the reasons why a discrepancy between mRNA expression and protein levels were observed after treatment with VA692, suggesting that some expressional changes can occur at protein level. One reason for this inconsistency may be related to a translational regulation, or, for instance, to the post-translational modification of proteins, as phosphorylation, glycosylation or methylation [46]. Further studies should be performed to confirm these possible explanations and to understand the implication of VA692 in this sense.

For the global analysis of chondrocytes proteome, we performed a quantitative study using iTRAQ technique, in T/C-28a2 cells treated with celecoxib and VA692 in presence of IL-1 $\beta$. To our knowledge, this is the first pharmacoproteomic study performed in T/C-28a2 cells. The experiment allowed us to create a quantitative profile of chondrocyte intracellular protein changes managed by our drugs of interest; moreover, the Venn analysis led us to discriminate the modulation of proteins related to a specific treatment performed, demonstrating the real impact of compound VA692 on T/C-28a2 proteome. On the basis of our results, celecoxib was able to modulate only 7 proteins in a significant manner. To date, only some in vitro experiments were performed in carcinoma cell lines and reported the antiproliferative and antitumor activities of celecoxib; these studies underlined a modulation of celecoxib of non-COX-2 protein targets involved in tumorigenesis [47-49]. These studies can not be compared with our results neither for the type of cells employed nor for the proteomic strategy used. More interesting and encouraging results were obtained testing compound VA692. The new drug modulated 123 proteins, 53 were down-regulated and 70 were up-regulated. Among the down-regulated proteins, some with structural function (VIM, ACTN1, VINC, FLN, COF) were identified. The architecture of cytoskeleton consists of a network of actin microfilaments, microtubules and vimentin intermade filaments and play significant roles in chondrocytes physiology, in particular in biomechanics and in mechanotransduction signaling [50]. Different studies reported altered vimentin levels in chondrocytes as a consequence of a particular 
stress or articular damage. Increased vimentin fragments were detected in OA rat model and in human cartilage from OA patients; this was correlated to a disruption in vimentin network [51,52]. High abundance of vimentin and of actin-remodeling proteins as cofilin and transgelin were observed after a proteomic quantification of human normal chondrocytes [53]; moreover, higher accumulation of nuclear actin is considered a marker of cellular senescence [53]. These accumulating evidence led us to consider these proteins as OA progression- and senescence-related proteins. Recently, a paper studying the proteomic profile of human normal chondrocyte by twodimensional electrophoresis analysis reported an abundant icrease of intermediate filament vimentin after stimulus of the cells with IL-1 $\beta$ [54]. Similarly, in our work we observed an increase of vimentin protein fragments in IL-1 $\beta$-stimulated cells even, if in a not significant manner. VA692 was able to reduce the amount of these proteins in chondrocytes cell line subjected to a cytokine damaging stimulus; so we hypothesize that VA692 could have a role in restoring cytoskeleton organization following stress conditions.

HSP90 have been found involved in many processes contributing to age-related changes in cartilage ECM as MMPs expression, NO synthesis and production of COX-2 [55]. Data from literature described altered protein levels of HSP90B in OA chondrocytes; indeed, results from proteomic analysis showed increased HSP90B and GRP78 proteins in diseased cells [56]. In addition, an in vitro study of proteome strategy in T/C-28a4 cell line demonstrated the increase of HSP70 and HSP90 following a negative stress [57]; this result confirm the up-regulation of HSP10 in T/C-28a2 cell line induced by the stimulus of IL-1 $\beta$ in our study. On the other hand, a down-regulation of HSP90 (A and B), HSP7C as well as of some proteins involved in glycolysis process were observed when our cells were pharmacologically treated with VA692. Indeed, the increased expression of these proteins seems to be related to the impaired glucose metabolism that occur in chondrocytes under stress conditions or during OA cartilage degradation [56]. Moreover, HSP90 has also been found to accelerate NO synthesis and apoptosis in OA pathogenesis and after IL-1 $\beta$ stimulus [56,58]. These findings highlight the role of the studied chaperones proteins in mediating cellular 
responses under stress conditions, and in particular we demonstrated the ability of VA692 to modulate them speculating its possible role in regulation of chondrocyte metabolism.

Another result obtained by the proteomic analysis was the up-regulation of $\mathrm{Cu}-\mathrm{Zn}$ SOD or SOD-1 in IL-1 $\beta$-stimulated chondrocytes. $\mathrm{Cu}-\mathrm{Zn}$ SOD is the intracellular isoform of SOD principally found in the cytosol and in the nucleus of the cells, but also in the mitochondrial intermembrane space, where exerts its mitochondrial functions against oxidative stress [58]. Little is known about the modulation of $\mathrm{Cu}-\mathrm{Zn} \mathrm{SOD}$ in chondrocyte cultures and, to our knowledge, this is the first report observing its regulation in IL-1 $\beta$-stimulated chondrocyte cell line at proteome level. An in vitro experiment on human normal chondrocyte cultures observed the modulation of IL- $1 \beta$ in increasing SOD-2 protein [54]; these data support our results demonstrating the effect of the pro-inflammatory cytokine on SOD family, despite a different type of cells have been employed.

After the treatment with the new compound VA692, we found a higher expression of SOD-1. These findings suggest that the anti-oxidant defense increased to counteract the increased ROS levels produced following a cytokine stimulus and underline the ability of our pharmacological treatment. This result, taken together with our previous described data, confirms the role of VA692 in T/C28a2 anti-oxidant system.

CALM, CALU, RCN, CALR and CALD1 are multifunctional $\mathrm{Ca}^{2+}$ transducer and $\mathrm{Ca}^{2+}$-sensor proteins and this is the basis of the competence of these proteins to transduce $\mathrm{Ca}^{2+}$ signals and mediates many of the regulatory effects of $\mathrm{Ca}^{2+}$. These proteins are expressed in all eukaryotic cells, participating in signaling pathways and regulating many crucial physiological processes [59]. An in vitro study on human fibroblasts affirmed the strong interaction between IL-1 and calciumbinding proteins, resulting in generation of calcium signals; this link was considered essential for activation of signaling pathways including the production of matrix protein degrading proteases [60]. This could explain and support our results about the up-regulation of proteins calmodulin and reticulocalbins following IL-1 $\beta$ stimulus; however the studies are not comparable due to the different used cell types, and more, the role of calcium-binding proteins in chondrocytes is not well 
elucidated [61]. Then, we observed a significant up-regulation of CALM, CALU, RCN, CALR and CALD1 after the treatment of the T/C-28a2 cell line with VA692. The raised levels of these proteins regulators of $\mathrm{Ca}^{+}$could be related to the increase of their activity as a consequence of IL-1 $\beta$ availability, responsible for the increase in calcium signal [60], which is maintained also in the presence of the drug. These data lead us to speculate regarding the putative role of VA692 in regulating calcium signal under stress conditions.

Interestingly, some proteins involved in osteblast differentiation, such as CLH1 and FSN, were also identified in our proteomic analysis. Osteoclasts are multi-nucleated cells and their physiological function is to degrade bone matrix; this bone-resorbing activity is essential for controlling bone development and turnover. Osteoclasts differentiation is regulated by osteoblasts for both bone mineralization and osteoclast function, by the activation of receptor activator of nuclear factor B (RANK) [62]. Clathrin plays a key role in many different signaling pathways, as RANK, mediating a broad range of cellular processes from embryonic development, cell homeostasis and metabolism and osteoaclastogenesis [63]. No evidence is available concerning the implication of these proteins in OA; however, an analysis performed on intracellular proteome of OA chondrocytes reported a significant decrease of periostin, known to be associated to tissue mineralization, after IL-1 $\beta$ stimulus; the authors hypothesized that the altered synthesis of that protein could be explain the pathological events that occur in OA chondrocytes as cell hypertrophy and matrix mineralization [64]; however, this report is not comparable with our study. Our results didn't show any significant modulation of CLH and FSN in IL-1 $\beta$-stimulated T/C-28a2, on the other hand we observed a significant reduction of those proteins after treatment with VA692. Although its just a preliminary result, the modulation induced by our compound of interest could hypothesize its role in reducing bone mineralization; additional studies are needed to better elucidate this aspect.

In conclusion, on the basis of our results, the novel compound VA692 has more beneficial effect compared to celecoxib on the modulation of the inflammatory response and the redox system. The proteomic analysis performed in this work provides new information about the effect of VA692 on 
human T/C-28a2 cell line intracellular proteome, demonstrating the usefulness of this approach in the identification and quantifications of several proteins. Some of them had not previously reported to be produced by chondrocytes, for instance proteins involved in calcium metabolism. However, the study presents a limitation due to the lack of additional techniques to apply on protein extracts, as western blot or qRT-PCR, in order to confirm and support the modulation observed in chondrocytes proteome; indeed, candidate proteins need to be validated by an orthogonal technique before their biological roles are pursued. The results obtained in T/C-28a2 cell line encourage to carry on the experiments evaluating the proteomic profile also in OA chondrocyte primary cultures following VA692-treatment. These points represent the fundamental for future studies.

Further in vitro and in vivo experiments are necessary to confirm if VA692 could present any advantages over other selective COX-2 inhibitors already available before its clinical implementation. 


\section{Acknowledgments}

This research did not receive any specific grant from funding agencies in the public, commercial, or not-for-profit sectors. 


\section{Authors' contributions}

The authors declare to have participated in the drafting of this paper as specified below:

Sara Cheleschi: performed cell culture, cell treatment, qRT-PCR, flow cytometry, data analysis, contributed to write protocol and article.E-mail: saracheleschi@hotmail.com

Valentina Calamia: performed cell treatment for proteomic experiments, proteomic data analysis, contributed to write protocol and article. E-mail: vcalami@gmail.com

Mercedes Fernandez-Moreno: performed flow cytometry, data analysis, contributed to write protocol and article. E-mail: Mercedes.Fernandez.Moreno@sergas.es

Mariangela Biava: performed the optimization of the synthetic procedure of VA692 in view of its scale up synthesis. E-mail: mariangela.biava@uniroma1.it

Antonio Giordani: performed PDB search and the characterization of VA692 by means of mass spectroscopy). E-mail: antonio.giordani@rottapharm.com

Antonella Fioravanti: contributed into writing the protocol and the article. E-mail: fioravanti7@virgilio.it

Maurizio Anzini: performed drug design and early synthesis of VA692, coordinated the Medicinal Chemistry Unit and contributed to the writing of the article).E-mail: maurizio.anzini@ unisi.it

Francisco Blanco: contributed into writing the protocol and the article. E-mail: fblagar@ sergas.es 


\section{Competing interest statement}

The authors affirm that there are no conflict of interest. 


\section{References}

1. Y. Zhang, J.M. Jordan, Epidemiology of osteoarthritis, Clin. Geriatr. Med. 26 (2010) 355369. doi: 10.1016/j.cger.2010.03.001.

2. V.B. Kraus, F.J. Blanco, M. Englund, M.A. Karsdal, L.S. Lohmander, Call for standardized definitions of osteoarthritis and risk stratification for clinical trials and clinical use, Osteoarthritis Cartilage. 23 (2015) 1233-1241. doi: 10.1016/j.joca.2015.03.036.

3. M.C. Hochberg, R.D. Altman, K.T. April, M. Benkhalti, G Guyatt, J McGowan, et al, American College of Rheumatology 2012 recommendations for the use of nonpharmacologic and pharmacologic therapies in osteoarthritis of the hand, hip, and knee, Arthritis. Care. Res. 64 (2012) 465-474.

4. T.E. McAlindon, R.R. Bannuru, M.C. Sullivan, N.K. Arden, F. Berenbaum, S.M. BiermaZeinstra, et al, OARSI guidelines for the non-surgical management of knee osteoarthritis, Osteoarthritis Cartilage. 22 (2014) 363-388. doi: 10.1016/j.joca.2014.01.003.

5. C. Ding, Do NSAIDs affect the progression of osteoarthritis? Inflammation. 26 (2002) 139142 .

6. J.R. Parfitt, D.K. Driman, Pathological effects of drugs on the gastrointestinal tract: a review, Hum. Pathol. 38 (2007) 527-536.

7. S. Harirforoosh, W. Asghar, F. Jamali. Adverse effects of nonsteroidal anti-inflammatory drugs: an update of gastrointestinal, cardiovascular and renal complications, J. Pharm. Sci. 16 (2013) 821-847.

8. K.C. Zimmermann, M. Sarbia, K. Schrör, A.A. Weber. Constitutive cyclooxygenase-2 expression in healthy human and rabbit gastric mucosa, Mol. Pharmacol. 54 (1998) 536540.

9. M.J. Shield, Anti-inflammatory drugs and their effects on cartilage synthesis and renal function, Eur. J. Rheumatol. Inflamm. 13 (1993) 7-16. 
10. R.L. Smith, G. Kajiyama, N.E. Lane, Nonsteroidal antiinflammatory drugs: effects on normal and interleukin 1 treated human articular chondrocyte metabolism in vitro, J. Rheumatol. 22 (1995) 1130-1137.

11. J.T. Dingle, The effects of NSAID on the matrix of human articular cartilages, Z. Rheumatol. 58 (1999) 125-129.

12. D.L. DeWitt, Cox-2-Selective Inhibitors: The New Super Aspirins, Mol. Pharm. 55 (1999) 625-631.

13. C.J. Hawkey, COX-2 inhibitors, Lancet. 353 (1999) 307-314.

14. C.O. Bingham III, Development and clinical application of COX-2-selective inhibitors for the treatment of osteoarthritis and rheumatoid arthritis, Cleve. Clin. J. Med. 691 (2002) SI512.

15. S.C. Mastbergen, N.W. Jansen, J.W. Bijlsma, F.P. Lafeber, Differential direct effects of cyclo-oxygenase-1/2 inhibition on proteoglycan turnover of human osteoarthritic cartilage: an in vitro study, Arthritis. Res. Ther. 8 (2006) R2.

16. K. Matsuda, S. Nakamura, T. Matsushita, Celecoxib inhibits nitric oxide production in chondrocytes of ligament-damaged osteoarthritic rat joints, Rheumatol. Int. 26 (2006)991995.

17. Y. Ou, C. Tan, H. An, D. Jiang, Z. Quan, K. Tang, X. Luo, Selective COX-2 inhibitor ameliorates osteoarthritis by repressing apoptosis of chondrocyte, Med. Sci. Monit. 18 (2012) 247-252.

18. A.J. Scheen, Withdrawal of rofecoxib (Vioxx): what about cardiovascular safety of cox-2selective non-steroidal anti-inflammatory drugs? Rev. Med. Liege. 59 (2004) 565-569.

19. R. De Vecchis, C. Baldi, G. Di Biase, C. Ariano, C. Cioppa, A. Giasi, et al, Cardiovascular risk associated with celecoxib or etoricoxib: a meta-analysis of randomized controlled trials which adopted comparison with placebo or naproxen, Minerva. Cardioangiol. 62 (2014) 437-448. 
20. S. Fries, T. Grosser, T.S. Price, J.A. Lawson, S. Kapoor, S. De Marco, et al, Marked interindividual variability in the response to selective inhibitors of cyclooxygenase-2, Gastroenterology. 130 (2006) 55-64.

21. A. Cappelli, M. Anzini, M. Biava, et al, 3-Substituted-1,5-Diaryl-2-alkyl-pyrroles Highly Selective and Orally Effective COX-2 Inhibitors, PCT. Int. Appl. 2008, WO2008014821.

22. M. Biava, G.C. Porretta, A. Cappelli, S. Vomero, F. Manetti, M. Botta, et al, 1,5Diarylpyrrole-3-acetic acids and esters as novel classes of potent and highly selective cyclooxygenase-2 inhibitors, J. Med. Chem. 48 (2005) 3428-3432.

23. M. Anzini, M. Rovini, A. Cappelli, S. Vomero, F. Manetti, M. Botta, et al, Synthesis, Biological Evaluation, and Enzyme Docking Simulations of 1,5-Diarylpyrrole-3alkoxyethyl Ethers as Highly Selective COX-2 Inhibitors Endowed with Anti-Inflammatory and Antinociceptive Activity, J. Med. Chem. 51 (2008) 4476-4481. doi: $10.1021 / \mathrm{jm} 800084 \mathrm{~s}$.

24. M. Anzini, A. Di Capua, S. Valenti, S. Brogi, M. Rovini, G. Giuliani, et al, Novel Analgesic/Anti-Inflammatory Agents: 1,5-Diarylpyrrole Nitrooxyalkyl Ethers and Related Compounds as Cyclooxygenase-2 Inhibiting Nitric Oxide Donor, J. Med. Chem. 56 (2013) 3191-206. doi: 10.1021/jm301370e.

25. S. Cheleschi, N.A. Pascarelli, G. Valacchi, A. Di Capua, M. Biava, G. Belmonte, et al, Chondroprotective effect of three different classes of anti-inflammatory agents on human osteoarthritic chondrocytes exposed to IL-1 $\beta$, Int. Immunopharmacol. 28 (2015) 794-801. doi: 10.1016/j.intimp.2015.07.003.

26. M.B. Goldring, J.R. Birkhead, L.F. Suen, R. Yamin, S. Mizuno, J. Glowacki, et al, Interleukin-1 beta-modulated gene expression in immortalized human chondrocytes, J. Clin. Invest. 94 (1994) 2307-2316.

27. J.H. Kellgren, J.S. lawrence, Radiological assessment of osteoarthrosis, Ann. Rheum. Dis. 16 (1957) 494-502. 
28. R. Altman, G. Alarcón, D. Appelrouth, D. Bloch, D. Borenstein, K. Brandt, et al, The American College of Rheumatology criteria for the classification and reporting of osteoarthritis of the hip, Arthritis. Rheum. 34 (1991) 505-514.

29. Z.Yuan, B. Zhao, Y. Zhang, Effects of dimethylsulfoxide on behavior and antioxidant enzymes response of planarian Dugesia japonica, Toxicol. Ind. Health. 28 (2012) 449-457.

30. J. Vandesompele, K. De Preter, Pattyn F, et al, Accurate normalization of real-time quantitative RT-PCR data by geometric averaging of multiple internal control genes. Genome Biol 3 (2002) :RESEARCH0034.

31. A. Santoro, J. Conde, M. Scotece, V. Abella., V. López, J. Pino, et al, Choosing the right chondrocyte cell line: Focus on nitric oxide, J. Orthop. Res. 33 (2015) 1784-1788. doi: 10.1002/jor.22954.

32. N. Schmidt, A. Pautz, J. Art, P. Rauschkolb, M. Jung, G. Erkel, et al, Transcriptional and post-transcriptional regulation of iNOS expression in human chondrocytes, Biochem. Pharmacol. 79 (2010) 722-732. doi: 10.1016/j.bcp.2009.10.012.

33. S.C. Mastbergen, A.C. Marijnissen, M.E. Vianen, B. Zoer, P.M. van Roermund, J.W. Bijlsma, F.P, Lafeber, Inhibition of COX-2 by celecoxib in the canine groove model of $\begin{array}{lllll}\text { osteoarthritis, } & \text { Rheumatology } & \text { (Oxford). } & 45 & \text { (2006) }\end{array}$ DOI:10.1093/rheumatology/kei187

34. T.N. de Boer, A.M. Huisman, A.A. Polak, A.G. Niehoff, A.C. van Rinsum, D. Saris, et al, The chondroprotective effect of selective COX-2 inhibition in osteoarthritis: ex vivo evaluation of human cartilage tissue after in vivo treatment, Osteoarthritis Cartilage. 17 (2009) 482-488. doi: 10.1016/j.joca.2008.09.002.

35. S.C. Mastbergen, F.P. Lafeber, J.W. Bijlsma, Selective COX-2 inhibition prevents proinflammatory cytokine-induced cartilage damage, Rheumatology (Oxford). 41 (2002) 801-808. 
36. H. Cho, A. Walker, J. Williams, K.A. Hasty, Study of osteoarthritis treatment with antiinflammatory drugs: cyclooxygenase-2 inhibitor and steroids, Biomed. Res. Int. 2015 (2015) 595273. doi: 10.1155/2015/595273.

37. C. Sanchez, M.M. Mateus, M.P. Defresne, et al, Metabolism of human articular chondrocytes cultured in alginate beads. Long term effects of interleukin 1beta and nonsteroidal antiinflammatory drugs, J. Rheumatol. 29 (2002) 772-782.

38. F. Héraud, A. Héraud, M.F. Harmand, Apoptosis in normal and osteoarthritic human articular cartilage, Ann. Rheum. Dis. 59 (2000) 959-965.

39. J. Yang, Y. Lu, A. Guo, Platelet-rich plasma protects rat chondrocytes from interleukin-1 $\beta$ induced apoptosis, Mol. Med. Rep. 14 (2016) 4075-4082. doi: 10.3892/mmr.2016.5767.

40. Z. Li, D. Meng, G. Li, J. Xu, J. Xu, K. Tian, Y. Li, Celecoxib Combined with Diacerein Effectively Alleviates Osteoarthritis in Rats via Regulating JNK and p38MAPK Signaling Pathways, Inflammation. 38 (2015) 1563-1572. doi: 10.1007/s10753-015-0131-3.

41. Y.E. Henrotin, P. Bruckner, J.P. Pujol, The role of reactive oxygen species in homeostasis and degradation of cartilage, Osteoarthritis. Cartilage. 11 (2003) 747755.

42. C.M. Davies, F. Guilak, J.B. Weinberg, B. Fermor, Reactive nitrogen and oxygen species in interleukin-1-mediated DNA damage associated with osteoarthritis, Osteoarthritis. Cartilage. 16 (2008) 624-630.

43. S. Ozgocmen, O. Ardicoglu, H. Erdogan, et al, In vivo effect of celecoxib and tenoxicam on oxidant/anti-oxidant status of patients with knee osteoarthritis, Ann. Clin. Lab. Sc. 35 (2005) 137-143.

44. M.Y. Burak Cimen, O.B. Cimen, G. Eskandari, et al, In vivo effects of meloxicam, celecoxib, and ibuprofen on free radical metabolism in human erythrocytes, Drug. Chem. Toxicol. 26 (2003) 169-176. 
45. V. Calamia, P. Fernández-Puente, J. Mateos et al, Pharmacoproteomic study of three different chondroitin sulfate compounds on intracellular and extracellular human chondrocyte proteomes, Mol. Cel.1 Proteomics. 11(2012) M111.013417.

46. Q. Zhang, T. Dai, L. Zhang, et al, Identification of potential biomarkers for predicting acute dermal irritation by proteomic analysis, J. Appl. Toxicol. 31 (2011) 762-772.

47. B. Buecher, D. Bouancheau, A. Broquet, S. Bezieau, M.G. Denis, C. Bonnet, et al, Growth inhibitory effect of celecoxib and rofecoxib on human colorectal carcinoma cell lines, Anticancer. Res. 25 (2005) 225-233.

48. J. Lou, N. Fatima, Z. Xiao, S. Stauffer, G. Smythers, P. Greenwald, I.U. Ali, Proteomic profiling identifies cyclooxygenase-2-independent global proteomic changes by celecoxib in colorectal cancer cells, Cancer. Epidemiol. Biomarkers. Prev. 15 (2006) 1598-1606.

49. F. Rezaie, M. Salimi, M.H. Ghahremani, B. Vaziri, Potential molecular targets in chemopreventative action of celecoxib: a proteomics analysis of J774.A1 macrophage-like cell line, Mol. Biosyst. 7 (2011) 1306-1311. doi: 10.1039/c0mb00201a.

50. S. Lambrecht, G. Verbruggen, P.C. Verdonk, D. Elewaut, D. Deforce, Differential proteome analysis of normal and osteoarthritic chondrocytes reveals distortion of vimentin network in osteoarthritis, Osteoarthritis. Cartilage. 16 (2008) 163-173.

51. N. Capin-Gutierrez, P. Talamas-Rohana, A. Gonzalez-Roble, C. Lavalle-Montalvo, J.B. Kourí, Cytoskeleton disruption in chondrocytes from a rat osteoarthrosic (OA) induced model: its potential role in OA pathogenesis, Histol. Histopathol. 19 (2004) 1125-1132. doi: 10.14670/HH-19.1125.

52. C. Ruiz-Romero, M.J. Lopez-Armada, F.J. Blanco, Proteomic characterization of human normal articular chondrocytes: a novel tool for the study of osteoarthritis and other rheumatic diseases, Proteomics. 5 (2005) 3048-3059. DOI: 10.1002/pmic.200402106.

53. I.H. Kwak, H.S. Kim, O.R. Choi, M.S. Ryu, I.K. Lim, Nuclear accumulation of globular actin as a cellular senescence marker, Cancer. Res. 64 (2004) 572-580. 
54. B. Cillero-Pastor, C. Ruiz-Romero, B. Caramés, M.J. López-Armada, F.J. Blanco, Proteomic analysis by two-dimensional electrophoresis to identify the normal human chondrocyte proteome stimulated by tumor necrosis factor alpha and interleukin-1beta, Arthritis. Rheum. 62 (2010) 802-814.

55. Q.H. Ding, Y. Cheng, W.P. Chen, H.M. Zhong, X.H. Wang, Celastrol, an inhibitor of heat shock protein $90 \beta$ potently suppresses the expression of matrix metalloproteinases, inducible nitric oxide synthase and cyclooxygenase- 2 in primary human osteoarthritic chondrocytes, Eur. J. Pharmacol. 708 (2013) 1-7. doi: 10.1016/j.ejphar.2013.01.057.

56. C. Ruiz-Romero, V. Carreira, I. Rego, S. Remeseiro, M.J. López-Armada, F.J. Blanco, Proteomic analysis of human osteoarthritic chondrocytes reveals protein changes in stress and glycolysis, Proteomics. 8 (2008) 495-507. doi: 10.1002/pmic.200700249.

57. M.A. Elo, R.K. Sironen, K. Kaarniranta, S. Auriola, H.J. Helminen, M.J. Lammi, Differential regulation of stress proteins by high hydrostatic pressure, heat shock, and unbalanced calcium homeostasis in chondrocytic cells, J. Cell. Biochem. 79 (2000) 610-619.

58. P. Inarrea, H. Moini, D. Han, D. Rettori, I. Aguiló, M.A. Alava, et al, Mitochondrial respiratory chain and thioredoxin reductase regulate intermembrane $\mathrm{Cu}, \mathrm{Zn}$-superoxide dismutase activity: implications for mitochondrial energy metabolism and apoptosis, J. Biochem. 405 (2007) 173-179. DOI: 10.1042/BJ20061809.

59. D. Chin, A.R. Means, Calmodulin: a prototypical calcium sensor, Trends. Cell. Biol. 10 (2000) 322-328.

60. Q. Wang, M.T. Herrera Abreu, K. Siminovitch, G.P. Downey, C.A. McCulloch, Phosphorylation of SHP-2 regulates interactions between the endoplasmic reticulum and focal adhesions to restrict interleukin-1-induced Ca2+ signaling, J. Biol. Chem. 281 (2006) 31093-31105. DOI:10.1074/jbc.M606392200.

61. R. Wilson, E.L. Norris, B. Brachvogel, C. Angelucci, et al. Changes in the chondrocyte and extracellular matrix proteome during post-natal mouse cartilage development. Mol. Cell. Proteomics. 11 (2012) M111.014159. 
62. V. Nicolin, G. Baldini, R. Bareggi, et al, Morphological features of osteoclasts derived from a coculture system, J. Mol. Histol. 37 (2006) 171-177.

63. J.A. Ybe, Novel clathrin activity: developments in health and disease, Biomol. Concepts, 5 (2014) 175-182. doi: 10.1515/bmc-2013-0040.

64. V. Calamia, B. Rocha, J. Mateos, P. Fernández-Puente, C. Ruiz-Romero, F.J. Blanco, Metabolic labeling of chondrocytes for the quantitative analysis of the interleukin-1-beta-mediated modulation of their intracellular and extracellular proteomes. J. Proteome. Res. 10 (2011) 3701-3711. doi: $10.1021 / \mathrm{pr} 200331 \mathrm{k}$. 


\section{Figure Legends}

Figure 1: Chemical structures of celecoxib, 1,5-diarylpyrrole-3-alkoxyethyl ethers (1), VA694 (2), and VA692 (3).

Figure 2. Inflammatory modulation. Genetic expression levels of COX-2, IL-1 $\beta$, IL-6 and IL-8 evaluated in T/C-28a2 (A), and in HAC (Human articular chondrocytes) (B). The gene expression was referenced to the ratio of the value of interest and basal condition; the value of basal conditions was reported equal to 1 . (C) Total amount of $\mathrm{PGE}_{2}(\mathrm{pg} / \mathrm{ml})$ detected in the culture medium of T/C28a2 and in HAC. The cells were incubated in presence of celecoxib (Cel) and VA692 at $1 \mu \mathrm{M}$ with a 2 hour of pre-treatment with IL-1 $\beta(5 \mathrm{ng} / \mathrm{ml})$. Data were expressed as mean \pm SD of triplicate values. ${ }^{\circ \circ} \mathrm{p}<0.01,{ }^{\circ \circ \circ} \mathrm{p}<0.001 \mathrm{IL}-1 \beta$ versus basal condition (Basal, cells without treatment). * $\mathrm{p}<0.05, * * \mathrm{p}<0.01, * * * \mathrm{p}<0.001$ celecoxib or VA692 treatment versus IL-1 $\beta$. Ba. = basal condition.

Figure 3. ROS production/response and Apoptotis detection. (A) The production levels of mitochondrial superoxide anion were analyzed using MitoSox Red staining. (B-C) Expression levels of SOD-2 and CAT in T/C-28a2 (B) and in HAC (Human articular chondrocytes) (C). The gene expression and the production of superoxide anion were referenced to the ratio of the value of interest and basal condition; the value of basal conditions was reported equal to 1. (D) Western blot of SOD-2 in T/C28a2; a representative immunoblotting image and densitometric analysis of SOD-2 protein levels. The ratio of protein level was referenced to the ratio of the value of interest and basal condition. The value of basal conditions was reported equal to 1. (E) Apoptosis measured with Annexin-V-FITC assay: data were expressed as percentage of positive cells for Annexin-V and propidium iodide (PI). The ratio of apoptosis was referenced to the ratio of the value of interest and basal condition. The value of basal conditions was reported equal to 1 .

Cells were incubated in presence of celecoxib $(\mathrm{Cel})$ and VA692 at $1 \mu \mathrm{M}$ with a 2 hour of pretreatment with IL-1 $\beta(5 \mathrm{ng} / \mathrm{ml})$. Data were expressed as mean \pm SD of triplicate values. ${ }^{\circ} \mathrm{p}<0.05$, ${ }^{\circ}$ $\mathrm{p}<0.01,{ }^{\circ \circ \circ} \mathrm{p}<0.001 \mathrm{IL}-1 \beta$ versus basal condition (Basal, cells without treatment). ${ }^{*} \mathrm{p}<0.05$, ** $\mathrm{p}<0.01, * * * \mathrm{p}<0.001$ IL-1 $\beta$ celecoxib or VA692 treatment versus IL-1 $\beta$. 
Figure 4. Data mining for proteomic analysis performed in proteome of $\mathrm{T} / \mathrm{C}-28 \mathrm{a} 2$ cell line treated for 48 hours with celecoxib and VA692 $(1 \mu \mathrm{M})$ in presence of IL-1 $\beta$ (2 hours of pre-treatment) $(5$ $\mathrm{ng} / \mathrm{ml}$ ), according to Gene Ontology annotation. Component pie charts indicating the biological processes in which the identified proteins are involved (A) and their cellular localization (B). Venn diagram represents proteins exclusively or commonly modulated by VA692 and IL-1 $\beta$ (C).

Figure 5. STRING analysis of the 53 down-regulated proteins highlighted cell differentiation (red nodes) as the main altered process in VA692 treated cells (A). In panel B proteins involved in osteoblast differentiation are marked in red.

String analysis of the 70 up-regulated proteins highlighted protein organization (red nodes) as the main altered process in VA692 treated cells (C). In panel D proteins involved in protein translation are marked in red. 
Table 1. List of primers used for qRT-PCR.

\begin{tabular}{|c|c|c|}
\hline Gene & Primer sequence & Probe \\
\hline RPL13A-Forward & 5'-CAAGCGGATGAACACCAAC-3' & \multirow{2}{*}{ \#28 } \\
\hline RPL13A-Reverse & 5'-TGTGGGGCAGCATACCTC-3' & \\
\hline COX-2-Forward & 5'-CTTCACGCATCAGTTTTTCAAG-3' & \multirow{2}{*}{$\# 23$} \\
\hline COX-2-Reverse & 5'-TCACCGTAAATATGATTTAAGTCCAC-3' & \\
\hline$S O D$-2-Forward & 5'-CTGGACAAACCTCAGCCCTA-3' & \multirow{2}{*}{ \#22 } \\
\hline$S O D$-2-Reverse & 5'-TGATGGCTTCCAGCAACTC-3' & \\
\hline CAT-Forward & 5'-TCATCAGGGATCCCATATTGTT-3' & \multirow{2}{*}{$\# 76$} \\
\hline$C A T$-Reverse & 5'-TCAGATGTGTCTGAGGATTTCTCT-3' & \\
\hline$I L-1 \beta$-Forward & 5'-TACCTGTCCTGCGTGTTGAA-3' & \multirow{2}{*}{$\# 78$} \\
\hline$I L-1 \beta$-Reverse & 5'-TCTTTGGGTAATTTTTGGGATCT-3' & \\
\hline IL-6-Forward & 5'-GATGAGTACAAAAGTCCTGATCCA-3' & \multirow{2}{*}{$\# 40$} \\
\hline$I L$-6-Reverse & 5'-CTGCAGCCACTGGTTCTGT-3' & \\
\hline$I L$-8-Forward & 5'-GAGCACTCCATAAGGCACAAA-3' & \multirow{2}{*}{$\# 72$} \\
\hline$I L$-8-Reverse & 5'-ATGGTTCCTTCCGGTGGT-3' & \\
\hline
\end{tabular}


Table 2. IL-1 $\beta$-modulated proteins in T/C-28a2 proteome

\begin{tabular}{|c|c|c|c|c|c|c|c|}
\hline Score & $\begin{array}{c}\% \\
\text { Cov } \\
\end{array}$ & Accession $^{\#}$ & Name & Symbol & Peptides (95\%) & $\begin{array}{c}\text { IL vs } \\
\text { CTL_1 } \beta^{\$}\end{array}$ & P VALUE \\
\hline 50.24 & 62.7 & $\mathrm{P} 14618$ & Pyruvate kinase isozymes M1/M2 & KPYM & 29 & 0.5916 & 0.0004 \\
\hline 41.79 & 26.6 & P49327 & Fatty acid synthase & FAS & 20 & 0.7047 & 0.0348 \\
\hline 36.26 & 69 & P07355 & Annexin A2 & ANX2 & 29 & 0.5248 & 0.0011 \\
\hline 35.26 & 72.2 & P04406 & Glyceraldehyde-3-phosphate dehydrogenase & GAPD & 32 & 0.4875 & 0.0038 \\
\hline 33.39 & 70.8 & P06748 & Nucleophosmin & NPM & 32 & 2.576 & 0.0232 \\
\hline 32.2 & 55.9 & $\mathrm{P} 05787$ & Keratin. type II cytoskeletal 8 & CYK8 & 25 & 0.4875 & 0.0006 \\
\hline 31.21 & 49.4 & Q5VTE0 & Putative elongation factor 1 -alpha-like 3 & EF1A3 & 18 & 0.5808 & 0.0276 \\
\hline 24.01 & 53.7 & Q8NC51 & Plasminogen activator inhibitor 1 RNA-binding protein & PAIRB & 15 & 1.7378 & 0.0023 \\
\hline 23.95 & 80.5 & P63241 & Eukaryotic translation initiation factor $5 \mathrm{~A}-1$ & IF5A1 & 20 & 3.5318 & 0.0084 \\
\hline 22.31 & 53.7 & P05783 & Keratin. type I cytoskeletal 18 & CYK18 & 14 & 0.4246 & 0.002 \\
\hline 18.26 & 83.9 & P62158 & Calmodulin & CALM & 16 & 3.6219 & 0.0037 \\
\hline 26.36 & 64.8 & P09493 & Tropomyosin alpha-1 chain & TMSA & 17 & 2.0137 & 0.0453 \\
\hline 16.97 & 61 & Q07021 & Complement component $1 \mathrm{Q}$ subcomponent-binding protein mitochondrial & C1QBP & 15 & 2.3121 & 0.0204 \\
\hline 15.05 & 42.9 & Q14257 & Reticulocalbin-2 & $\mathrm{RCN} 2$ & 9 & 3.6983 & 0.0016 \\
\hline 14.85 & 52.5 & P51858 & Hepatoma-derived growth factor & HDGF & 7 & 2.421 & 0.0104 \\
\hline 14.63 & 36.7 & Q92945 & Far upstream element-binding protein 2 & FUBP2 & 9 & 1.4588 & 0.0302 \\
\hline 14.24 & 44.6 & P31948 & Stress-induced-phosphoprotein 1 & STIP1 & 7 & 2.421 & 0.0073 \\
\hline 14 & 57.7 & Q07955 & Serine/arginine-rich splicing factor 1 & SRSF1 & 8 & 2.0701 & 0.0372 \\
\hline 13.78 & 43.1 & P04083 & Annexin A1 & ANX1 & 8 & 0.5861 & 0.0054 \\
\hline 12.91 & 23.5 & P14314 & Glucosidase 2 subunit beta & GLU2B & 6 & 1.977 & 0.0436 \\
\hline 12 & 53.6 & Q00688 & Peptidyl-prolyl cis-trans isomerase FKBP3 & FKBP3 & 5 & 1.6293 & 0.0554 \\
\hline 11.3 & 48.1 & P00441 & Superoxide dismutase $[\mathrm{Cu}-\mathrm{Zn}]$ & SODC & 6 & 5.3456 & 0.0142 \\
\hline 11.26 & 46.2 & Q01105 & Protein SET & SET & 10 & 2.7797 & 0.016 \\
\hline 11.06 & 63.1 & P16949 & Stathmin & STMN1 & 5 & 1.977 & 0.0182 \\
\hline 10.41 & 48.8 & Q96C19 & EF-hand domain-containing protein D2 & EFHD2 & 7 & 2.208 & 0.0494 \\
\hline 10.1 & 66.7 & P61604 & $10 \mathrm{kDa}$ heat shock protein mitochondrial & $\mathrm{CH} 10$ & 6 & 2.3121 & 0.0357 \\
\hline 10.06 & 70.7 & Q04760 & Lactoylglutathione lyase & GLO1 & 5 & 2.7542 & 0.0363 \\
\hline
\end{tabular}




\begin{tabular}{|c|c|c|c|c|c|c|c|}
\hline 10.05 & 54.9 & Q9NX55 & Huntingtin-interacting protein $\mathrm{K}$ & HYPK & 5 & 3.0761 & 0.0193 \\
\hline 10 & 49.5 & P10599 & Thioredoxin & TXN & 7 & 2.2284 & 0.0467 \\
\hline 9.13 & 44.8 & Q96D15 & Reticulocalbin-3 & $\mathrm{RCN} 3$ & 5 & 3.46 & 0.0331 \\
\hline 8.66 & 31 & Q14847 & LIM and SH3 domain protein 1 & LASP1 & 5 & 2.1878 & 0.0352 \\
\hline 8.4 & 68.5 & $\mathrm{O} 75347$ & Tubulin-specific chaperone A & TBCA & 4 & 3.1623 & 0.0399 \\
\hline 8.38 & 32.3 & P54727 & UV excision repair protein RAD23 homolog B & RAD23B & 4 & 1.888 & 0.028 \\
\hline 8 & 71.3 & P07108 & Acyl-CoA-binding protein & RAD23B & 6 & 259648 & 0.0621 \\
\hline
\end{tabular}

${ }^{\#}$ Protein accession number according to Swiss-Prot database. ${ }^{\$}$ Average iTRAQ ratio representing the relative protein abundance in IL-1 $\beta$ cells vs basal conditions. quantified by ProteinPilot 3.0 software. A p value $\leq 0.05$ was accepted. 
Table 3. Celecoxib-modulated proteins in T/C-28a2 proteome

\begin{tabular}{|c|c|c|c|c|c|c|c|}
\hline Score & $\% \operatorname{Cov}$ & Accession \# & Name & Symbol & Peptides $(95 \%)$ & $\begin{array}{l}\text { IL+Cel+IL-1及 vs } \\
\text { basal condition }\end{array}$ & $P$ value \\
\hline 46.45 & 64.2 & P08670 & Vimentin & VIME & 41 & 1.5136 & 0.0158 \\
\hline 35.26 & 72.2 & P04406 & Glyceraldehyde-3-phosphate dehydrogenase & G3P & 32 & 1.9409 & 0.007 \\
\hline 31.21 & 49.4 & Q5VTE0 & Putative elongation factor 1 -alpha-like 3 & EF1A3 & 18 & 1.6293 & 0.0494 \\
\hline 21.35 & 51.5 & P07195 & L-lactate dehydrogenase B chain & LDHB & 13 & 2.1677 & 0.0074 \\
\hline 14.39 & 64.2 & Q02878 & 60S ribosomal protein L6 & RL6 & 8 & 1.977 & 0.0486 \\
\hline 6.03 & 24.2 & P09496 & Clathrin light chain A & CLCA & 7 & 0.8166 & 0.0096 \\
\hline 4.02 & 40 & Q15836 & Vesicle-associated membrane protein 3 & VAMP3 & 2 & 0.207 & 0.0493 \\
\hline
\end{tabular}

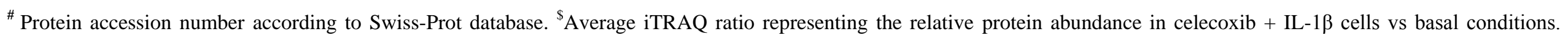
quantified by ProteinPilot 3.0 software. A p value $\leq 0.05$ was accepted. 
Table 4. VA692-modulated proteins in T/C-28a2 proteome

\begin{tabular}{|c|c|c|c|c|c|c|c|}
\hline Score & $\% \mathrm{Cov}$ & Accession $^{\#}$ & Name & Symbol & Peptides(95\%) & $\begin{array}{c}\text { IL+VA vs IL- } \\
1 \beta^{\$} \\
\end{array}$ & pvalue \\
\hline 120.75 & 53.8 & P35579 & Myosin-9 & MYH9 & 74 & 0.2999 & 0 \\
\hline 84.46 & 51.4 & Q09666 & Neuroblast differentiation-associated protein AHNAK & AHNK & 44 & 1.7504 & 0 \\
\hline 73.81 & 33.6 & P21333 & Filamin-A & FLNA & 39 & 0.50927 & 0 \\
\hline 68.67 & 61.6 & P12814 & Alpha-actinin-1 & ACTN1 & 49 & 0.5506 & 0.0083 \\
\hline 52.45 & 72.1 & $\mathrm{P} 11142$ & Heat shock cognate $71 \mathrm{kDa}$ protein & HSP7C & 33 & 0.51067 & 0.047 \\
\hline 51.67 & 58.3 & P19338 & Nucleolin & NUCL & 29 & 4.1515 & 0 \\
\hline 50.52 & 62.6 & $\mathrm{P} 07900$ & Heat shock protein HSP 90-alpha & HS90A & 28 & 0.31137 & 0.0215 \\
\hline 50.24 & 62.7 & $\mathrm{P} 14618$ & Pyruvate kinase isozymes M1/M2 & KPYM & 29 & 0.35685 & 0.0001 \\
\hline 53.95 & 32.2 & O75369 & Filamin-B & FLNB & 29 & 0.4193 & 0.0016 \\
\hline 46.45 & 64.2 & $\mathrm{P} 08670$ & Vimentin & VIME & 41 & 0.7178 & 0.0136 \\
\hline 41.79 & 26.6 & P49327 & Fatty acid synthase & FAS & 20 & 0.3392 & 0 \\
\hline 38.27 & 93.8 & P16401 & Histone H1.5 & $\mathrm{H} 15$ & 18 & 9.798 & 0.0013 \\
\hline 37.76 & 44.6 & P13639 & Elongation factor 2 & $\mathrm{EF} 2$ & 19 & 0.4895 & 0.0034 \\
\hline 36.12 & 23.9 & Q15149 & Plectin & PLEC & 20 & 0.3621 & 0.0009 \\
\hline 33.39 & 70.8 & P06748 & Nucleophosmin & NPM & 32 & 2.531 & 0.0004 \\
\hline 31.21 & 49.4 & Q5VTE0 & Putative elongation factor 1 -alpha-like 3 & EF1A3 & 18 & 0.486 & 0.0205 \\
\hline 31.04 & 89.7 & P62937 & Peptidyl-prolyl cis-trans isomerase A & PPIA & 32 & 3.4956 & 0.0131 \\
\hline 27.78 & 75.1 & $\mathrm{P} 60174$ & Triosephosphate isomerase & TPIS & 18 & 1.7996 & 0.0222 \\
\hline 27.6 & 46 & P12956 & X-ray repair cross-complementing protein 6 & XRCC6 & 14 & 0.486 & 0.0093 \\
\hline 27.47 & 36.1 & $\mathrm{P} 27816$ & Microtubule-associated protein 4 & MAP4 & 14 & 1.757 & 0.0044 \\
\hline 27.4 & 69.4 & P62258 & 14-3-3 protein epsilon & $1433 \mathrm{E}$ & 16 & 2.8063 & 0.0089 \\
\hline 27 & 86.8 & $\mathrm{P} 23528$ & Cofilin-1 & COF1 & 16 & 2.4281 & 0.0114 \\
\hline 24.98 & 63.3 & P09429 & High mobility group protein B1 & HMGB1 & 15 & 5.0249 & 0.0002 \\
\hline 24.95 & 34.2 & P46940 & Ras GTPase-activating-like protein IQGAP1 & IQGA1 & 11 & 0.2938 & 0.0002 \\
\hline 24.21 & 95.2 & P80723 & Brain acid soluble protein 1 & BASP1 & 11 & 3.7487 & 0.0001 \\
\hline 24.01 & 53.7 & Q8NC51 & Plasminogen activator inhibitor 1 RNA-binding protein & PAIRB & 15 & 2.5086 & 0.0001 \\
\hline 34.77 & 90.6 & P16403 & Histone H1.2 & $\mathrm{H} 12$ & 21 & 2.5784 & 0.0066 \\
\hline 23.95 & 80.5 & P63241 & Eukaryotic translation initiation factor $5 \mathrm{~A}-1$ & IF5A1 & 20 & 1.6417 & 0.0082 \\
\hline
\end{tabular}




\begin{tabular}{|c|c|c|c|c|c|c|c|}
\hline 23.13 & 25.3 & Q00610 & Clathrin heavy chain 1 & CLH1 & 12 & 0.4771 & 0.0032 \\
\hline 23.01 & 33.7 & $\mathrm{P} 07237$ & Protein disulfide-isomerase & PDIA1 & 15 & 1.8096 & 0.0171 \\
\hline 22.42 & 23.6 & Q01082 & Spectrin beta chain. brain 1 & SPTB2 & 11 & 0.2114 & 0.0051 \\
\hline 22.07 & 91.4 & P07737 & Profilin-1 & PROF1 & 16 & 2.0607 & 0.0057 \\
\hline 21.88 & 28.2 & $\mathrm{P} 22314$ & Ubiquitin-like modifier-activating enzyme 1 & UBA1 & 15 & 0.367 & 0.0082 \\
\hline 21.78 & 18.1 & P78527 & DNA-dependent protein kinase catalytic subunit & PRKDC & 10 & 0.3464 & 0.0369 \\
\hline 48.31 & 59.8 & $\mathrm{P} 08238$ & Heat shock protein HSP 90-beta & HS90B & 30 & 0.3981 & 0.0096 \\
\hline 21.72 & 34.7 & Q7KZF4 & Staphylococcal nuclease domain-containing protein 1 & SND1 & 12 & 0.4742 & 0.0055 \\
\hline 21.28 & 53 & $\mathrm{P} 27797$ & Calreticulin & CALR & 12 & 4.953 & 0 \\
\hline 20.24 & 45.4 & $\mathrm{P} 07910$ & Heterogeneous nuclear ribonucleoproteins $\mathrm{C} 1 / \mathrm{C} 2$ & HNRPC & 12 & 2.3478 & 0.0026 \\
\hline 20.2 & 26.4 & P55060 & Exportin-2 & $\mathrm{XPO} 2$ & 11 & 0.3311 & 0.0131 \\
\hline 20.2 & 26.4 & P55060 & Exportin-2 & $\mathrm{XPO} 2$ & 11 & 0.302 & 0.001 \\
\hline 19.76 & 34.7 & Q00839 & Heterogeneous nuclear ribonucleoprotein U & HNRPU & 11 & 0.5495 & 0.0204 \\
\hline 26.64 & 50.8 & P09651 & Heterogeneous nuclear ribonucleoprotein A1 & ROA1 & 19 & 2.2909 & 0.038 \\
\hline 18.26 & 83.9 & P62158 & Calmodulin & CALM & 16 & 2.647 & 0.0008 \\
\hline 18.18 & 80.6 & P62805 & Histone H4 & $\mathrm{H} 4$ & 19 & 1.6219 & 0.0224 \\
\hline 17.8 & 66 & $\mathrm{O} 43852$ & Calumenin & CALU & 10 & 3.396 & 0.0017 \\
\hline 16.97 & 61 & Q07021 & Complement component $1 \mathrm{Q}$ subcomponent-binding protein. mitochondrial & C1QBP & 15 & 2.5645 & 0.0417 \\
\hline 16.98 & 15.5 & O75643 & U5 small nuclear ribonucleoprotein $200 \mathrm{kDa}$ helicase & U520 & 8 & 0.3076 & 0.0009 \\
\hline 16.41 & 32.5 & Q08211 & ATP-dependent RNA helicase A & DHX9 & 11 & 0.3945 & 0.0243 \\
\hline 25.87 & 30.9 & $\mathrm{P} 35580$ & Myosin-10 & MYH10 & 13 & 0.4325 & 0.0034 \\
\hline 16.1 & 39.7 & $\mathrm{P} 48643$ & T-complex protein 1 subunit epsilon & TCPE & 8 & 0.4702 & 0.0177 \\
\hline 15.97 & 39.9 & $\mathrm{P} 13010$ & $\mathrm{X}$-ray repair cross-complementing protein 5 & XRCC5 & 8 & 0.497 & 0.027 \\
\hline 15.51 & 38.6 & Q14103 & Heterogeneous nuclear ribonucleoprotein D0 & HNRPD & 7 & 4.5823 & 0.0051 \\
\hline 15.4 & 18.5 & $\mathrm{P} 41252$ & Isoleucyl-tRNA synthetase. cytoplasmic & SYIC & 9 & 0.3048 & 0.0475 \\
\hline 15.05 & 42.9 & Q14257 & Reticulocalbin-2 & RCN2 & 9 & 2.5351 & 0.0004 \\
\hline 14.87 & 33 & $\mathrm{P} 39023$ & 60S ribosomal protein L3 & RL3 & 8 & 0.5598 & 0.0252 \\
\hline 14.85 & 52.5 & P51858 & Hepatoma-derived growth factor & HDGF & 7 & 2.0137 & 0.0102 \\
\hline 14.41 & 22.8 & Q92841 & Probable ATP-dependent RNA helicase DDX17 & DDX17 & 7 & 0.5058 & 0.0291 \\
\hline 14.24 & 44.6 & P31948 & Stress-induced-phosphoprotein 1 & STIP1 & 7 & 2.3893 & 0.0044 \\
\hline 14.1 & 20.2 & Q04637 & Eukaryotic translation initiation factor 4 gamma 1 & IF4G1 & 7 & 0.4152 & 0.0393 \\
\hline
\end{tabular}




\begin{tabular}{|c|c|c|c|c|c|c|c|}
\hline 14.06 & 27.2 & Q14697 & Neutral alpha-glucosidase $\mathrm{AB}$ & GANAB & 7 & 0.5445 & 0.0315 \\
\hline 14 & 57.7 & Q07955 & Serine/arginine-rich splicing factor 1 & SRSF1 & 8 & 1.8707 & 0.0255 \\
\hline 13.94 & 56 & $\mathrm{P} 24534$ & Elongation factor 1-beta & EF1B & 8 & 3.2463 & 0.0267 \\
\hline 13.93 & 24.2 & P18206 & Vinculin & VINC & 8 & 0.4742 & 0.0211 \\
\hline 13.91 & 38.1 & Q05682 & Caldesmon & CALD1 & 9 & 2.466 & 0.0018 \\
\hline 12.95 & 15.3 & Q14204 & Cytoplasmic dynein 1 heavy chain 1 & DYHC1 & 6 & 0.302 & 0.0021 \\
\hline 12.91 & 23.5 & $\mathrm{P} 14314$ & Glucosidase 2 subunit beta & GLU2B & 6 & 2.321 & 0.0059 \\
\hline 12.67 & 63.6 & O75822 & Eukaryotic translation initiation factor 3 subunit $\mathbf{J}$ & EIF3J & 7 & 2.5062 & 0.0058 \\
\hline 12.44 & 49.7 & P39019 & 40S ribosomal protein $\mathrm{S} 19$ & RS19 & 7 & 2.5923 & 0.0187 \\
\hline 13.83 & 41.3 & $\mathrm{O} 75475$ & PC4 and SFRS1-interacting protein & PSIP1 & 7 & 3.0523 & 0.0092 \\
\hline 12 & 53.6 & Q00688 & Peptidyl-prolyl cis-trans isomerase FKBP3 & FKBP3 & 5 & 2.4677 & 0.0007 \\
\hline 11.87 & 41.4 & P20042 & Eukaryotic translation initiation factor 2 subunit 2 & IF2B & 7 & 2.0953 & 0.0243 \\
\hline 11.76 & 15.2 & Q14974 & Importin subunit beta-1 & IMB1 & 7 & 0.5058 & 0.0119 \\
\hline 14.72 & 26 & $\mathrm{P} 14625$ & Endoplasmin & ENPL & 9 & 0.49178 & 0.0797 \\
\hline 11.53 & 33.6 & O43175 & D-3-phosphoglycerate dehydrogenase & SERA & 6 & 0.54 & 0.0797 \\
\hline 25.53 & 51.8 & P06753 & Tropomyosin alpha-3 chain & TPM3 & 16 & 2.7351 & 0.0549 \\
\hline 11.55 & 50.3 & $\mathrm{P} 05455$ & Lupus La protein & LA & 5 & 1.6444 & 0.07 \\
\hline 11.3 & 48.1 & $\mathrm{P} 00441$ & Superoxide dismutase $[\mathrm{Cu}-\mathrm{Zn}]$ & SODC & 6 & 3.0761 & 0.0051 \\
\hline 11.26 & 46.2 & Q01105 & Protein SET & SET & 10 & 2.1178 & 0.0125 \\
\hline 11.06 & 63.1 & P16949 & Stathmin & STMN1 & 5 & 2.6823 & 0.0009 \\
\hline 11.05 & 30.2 & Q14978 & Nucleolar and coiled-body phosphoprotein 1 & NOLC1 & 5 & 2.3137 & 0.045 \\
\hline 10.56 & 27.5 & $\mathrm{P} 25705$ & ATP synthase subunit alpha. mitochondrial & ATPA & 6 & 0.413 & 0.0201 \\
\hline 10.44 & 20.6 & P33991 & DNA replication licensing factor MCM4 & MCM4 & 5 & 0.4125 & 0.0441 \\
\hline 10.41 & 49 & $\mathrm{P} 05141$ & ADP/ATP translocase 2 & ADT2 & 6 & 0.381 & 0.0273 \\
\hline 30.49 & 91.4 & $\mathrm{P} 16402$ & Histone H1.3 & $\mathrm{H} 13$ & 18 & 3.1675 & 0.0048 \\
\hline 10.18 & 52.4 & P62841 & 40S ribosomal protein $\mathrm{S} 15$ & RS15 & 5 & 2.3271 & 0.1081 \\
\hline 10.13 & 37 & $\mathrm{P} 20810$ & Calpastatin & ICAL & 5 & 1.945 & 0.0164 \\
\hline 10.2 & 23 & O43776 & Asparaginyl-tRNA synthetase. cytoplasmic & SYNC & 5 & 0.302 & 0.0214 \\
\hline 10.1 & 66.7 & P61604 & $10 \mathrm{kDa}$ heat shock protein. mitochondrial & $\mathrm{CH} 10$ & 6 & 2.546 & 0.0104 \\
\hline 10.01 & 43.3 & P53999 & Activated RNA polymerase II transcriptional coactivator p15 & TCP4 & 5 & 2.3335 & 0.0244 \\
\hline 10.01 & 43.3 & P53999 & Activated RNA polymerase II transcriptional coactivator p15 & TCP4 & 5 & 2.9376 & 0.0144 \\
\hline
\end{tabular}




\begin{tabular}{|c|c|c|c|c|c|c|c|}
\hline 10 & 32.1 & Q13242 & Serine/arginine-rich splicing factor 9 & SRSF9 & 5 & 2.3959 & 0.0434 \\
\hline 16.14 & 63.6 & P26583 & High mobility group protein B2 & HMGB2 & 10 & 2.9589 & 0.008 \\
\hline 9.85 & 40.4 & P63244 & Guanine nucleotide-binding protein subunit beta-2-like 1 & GBLP & 5 & 0.5395 & 0.0298 \\
\hline 9.76 & 39 & Q15293 & Reticulocalbin-1 & RCN1 & 5 & 2.508 & 0.0036 \\
\hline 9.52 & 17.3 & O14980 & Exportin-1 & XPO1 & 5 & 0.332 & 0.0554 \\
\hline 9.26 & 27.8 & P50991 & T-complex protein 1 subunit delta & TCPD & 5 & 0.4966 & 0.0267 \\
\hline 9.24 & 48.9 & Q8WXX5 & DnaJ homolog subfamily $\mathrm{C}$ member 9 & DNJC9 & 5 & 1.9588 & 0.0332 \\
\hline 9.2 & 70.5 & P25398 & 40S ribosomal protein $\mathrm{S} 12$ & $\mathrm{RS} 12$ & 5 & 3.2509 & 0.0308 \\
\hline 9.17 & 17.8 & Q13428 & Treacle protein & TCOF & 5 & 2.5823 & 0.0396 \\
\hline 9.13 & 44.8 & Q96D15 & Reticulocalbin-3 & $\mathrm{RCN} 3$ & 5 & 2.1878 & 0.0108 \\
\hline 9.07 & 20.2 & Q9Y490 & Talin-1 & TLN1 & 4 & 0.492 & 0.0417 \\
\hline 8.96 & 58.3 & P62750 & $60 \mathrm{~S}$ ribosomal protein $\mathrm{L} 23 \mathrm{a}$ & RL23A & 5 & 1.393 & 0.0119 \\
\hline 8.76 & 37.5 & Q02543 & $60 \mathrm{~S}$ ribosomal protein $\mathrm{L} 18 \mathrm{a}$ & RL18A & 4 & 0.52 & 0.0343 \\
\hline 8.76 & 63.7 & P09382 & Galectin-1 & LEG1 & 6 & 2.0701 & 0.0281 \\
\hline 8.41 & 26.9 & $\mathrm{P} 06744$ & Glucose-6-phosphate isomerase & G6PI & 4 & 0.3105 & 0.0093 \\
\hline 8.4 & 36 & P50502 & Hsc70-interacting protein & F10A1 & 5 & 2.6303 & 0.0305 \\
\hline 8.1 & 23.2 & Q9NTJ3 & Structural maintenance of chromosomes protein 4 & SMC4 & 4 & 0.2148 & 0.045 \\
\hline 8.15 & 17.9 & Q9Y5B9 & FACT complex subunit SPT16 & $\mathrm{SP} 16 \mathrm{H}$ & 4 & 0.302 & 0.0376 \\
\hline 8.05 & 55.2 & P62851 & $40 \mathrm{~S}$ ribosomal protein $\mathrm{S} 25$ & $\mathrm{RS} 25$ & 4 & 3.5645 & 0.037 \\
\hline 8.01 & 30.1 & Q00059 & Transcription factor A. mitochondrial & TFAM & 4 & 2.5119 & 0.0336 \\
\hline 8 & 71.3 & $\mathrm{P} 07108$ & Acyl-CoA-binding protein & RAD23B & 6 & 2.1893 & 0.037 \\
\hline 9.52 & 42.5 & $\mathrm{P} 00338$ & L-lactate dehydrogenase A chain & LDHA & 7 & 0.3873 & 0.0439 \\
\hline 7.6 & 22.2 & Q15942 & Zyxin & ZYX & 4 & 2.7797 & 0.0103 \\
\hline 9.27 & 30.4 & Q99729 & Heterogeneous nuclear ribonucleoprotein A/B & ROAA & 5 & 2.2491 & 0.0222 \\
\hline 6.84 & 30.1 & P29966 & Myristoylated alanine-rich C-kinase substrate & MARCS & 3 & 1.8365 & 0.0699 \\
\hline 33.42 & 93.6 & $\mathrm{P} 10412$ & Histone H1.4 & $\mathrm{H} 14$ & 19 & 5.929 & 0.0187 \\
\hline 6.05 & 25.5 & $\mathrm{P} 49321$ & Nuclear autoantigenic sperm protein & NASP & 3 & 1.9409 & 0.0465 \\
\hline 5.86 & 11.4 & $\mathrm{P} 05023$ & Sodium/potassium-transporting ATPase subunit alpha-1 & AT1A1 & 3 & 0.6194 & 0.033 \\
\hline 5.54 & 28.3 & $\mathrm{P} 23588$ & Eukaryotic translation initiation factor 4B & IF4B & 4 & 1.977 & 0.0591 \\
\hline 5.15 & 71.5 & Q15121 & Astrocytic phosphoprotein PEA-15 & PEA15 & 3 & 2.466 & 0.0297 \\
\hline 5.04 & 36.5 & Q13442 & $28 \mathrm{kDa}$ heat- and acid-stable phosphoprotein & HAP28 & 4 & 2.355 & 0.0459 \\
\hline
\end{tabular}




\begin{tabular}{|c|c|c|c|c|c|c|c|}
\hline 4.91 & 47.3 & P00492 & Hypoxanthine-guanine phosphoribosyltransferase & HPRT & 2 & 0.1096 & 0.0307 \\
\hline 4.53 & 67.8 & P05204 & Non-histone chromosomal protein HMG-17 & HMGN2 & 2 & 8.2462 & 0.0134 \\
\hline 6.03 & 46.3 & $\mathrm{P} 42766$ & $60 \mathrm{~S}$ ribosomal protein L35 & RL35 & 4 & 2.5119 & 0.0258 \\
\hline 4 & 20.5 & Q8N163 & Protein KIAA1967 & K1967 & 2 & 0.0288 & 0.033 \\
\hline
\end{tabular}

\# Protein accession number according to Swiss-Prot database. ${ }^{\$}$ Average iTRAQ ratio representing the relative protein abundance in IL-1 $\beta$ cells vs basal conditions. quantified by ProteinPilot 3.0 software. A p value $\leq 0.05$ was accepted. 
Figure 1

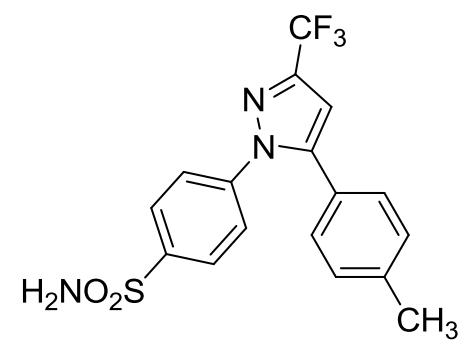

Celecoxib

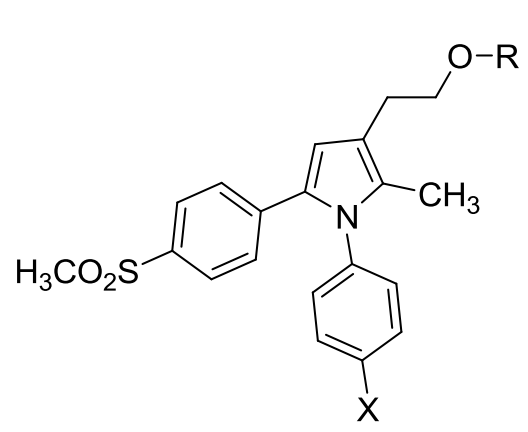

(1) $\mathrm{R}=\mathrm{Me}, \mathrm{Et}, \mathrm{Pr}$ $X=H, F$

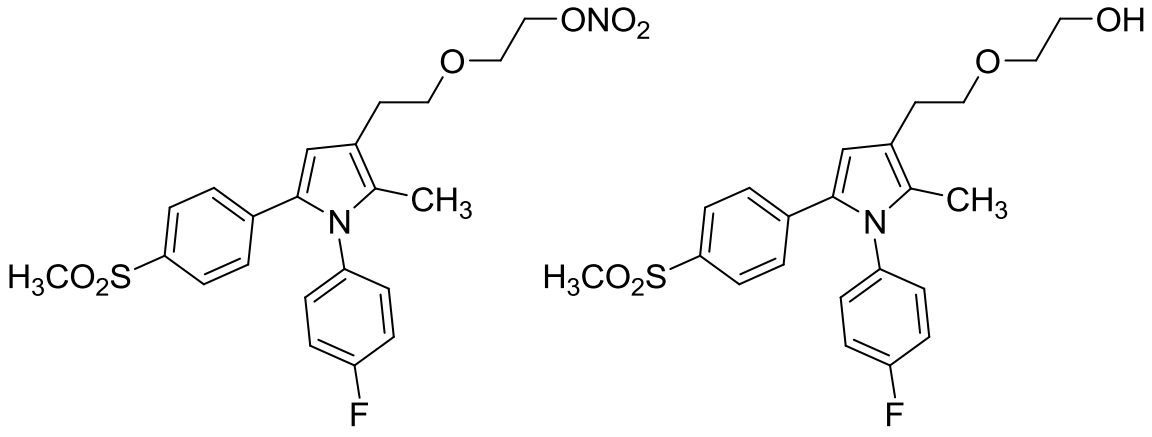

(2) VA 694

(3) VA 692 
Figure 2

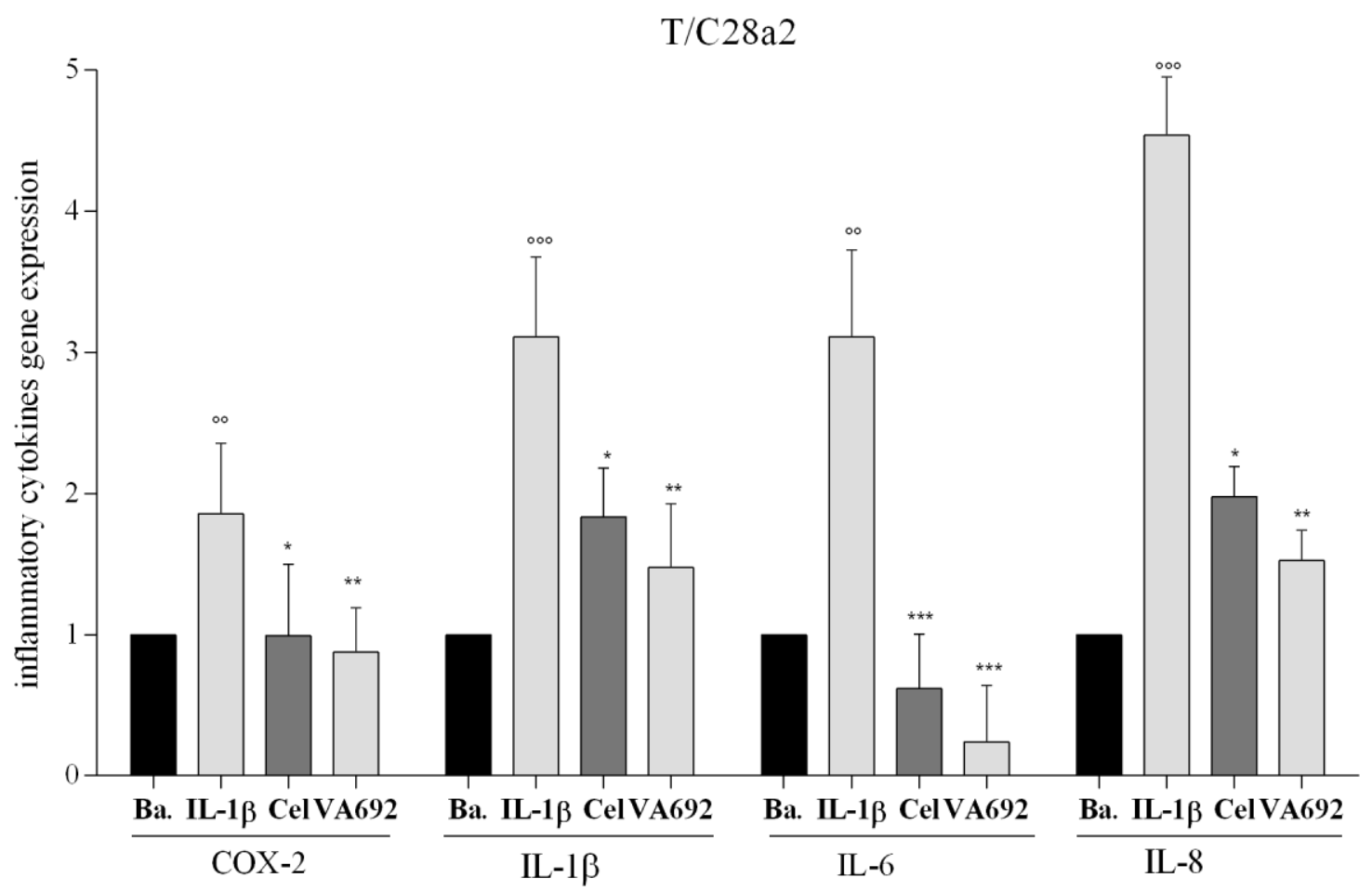

A

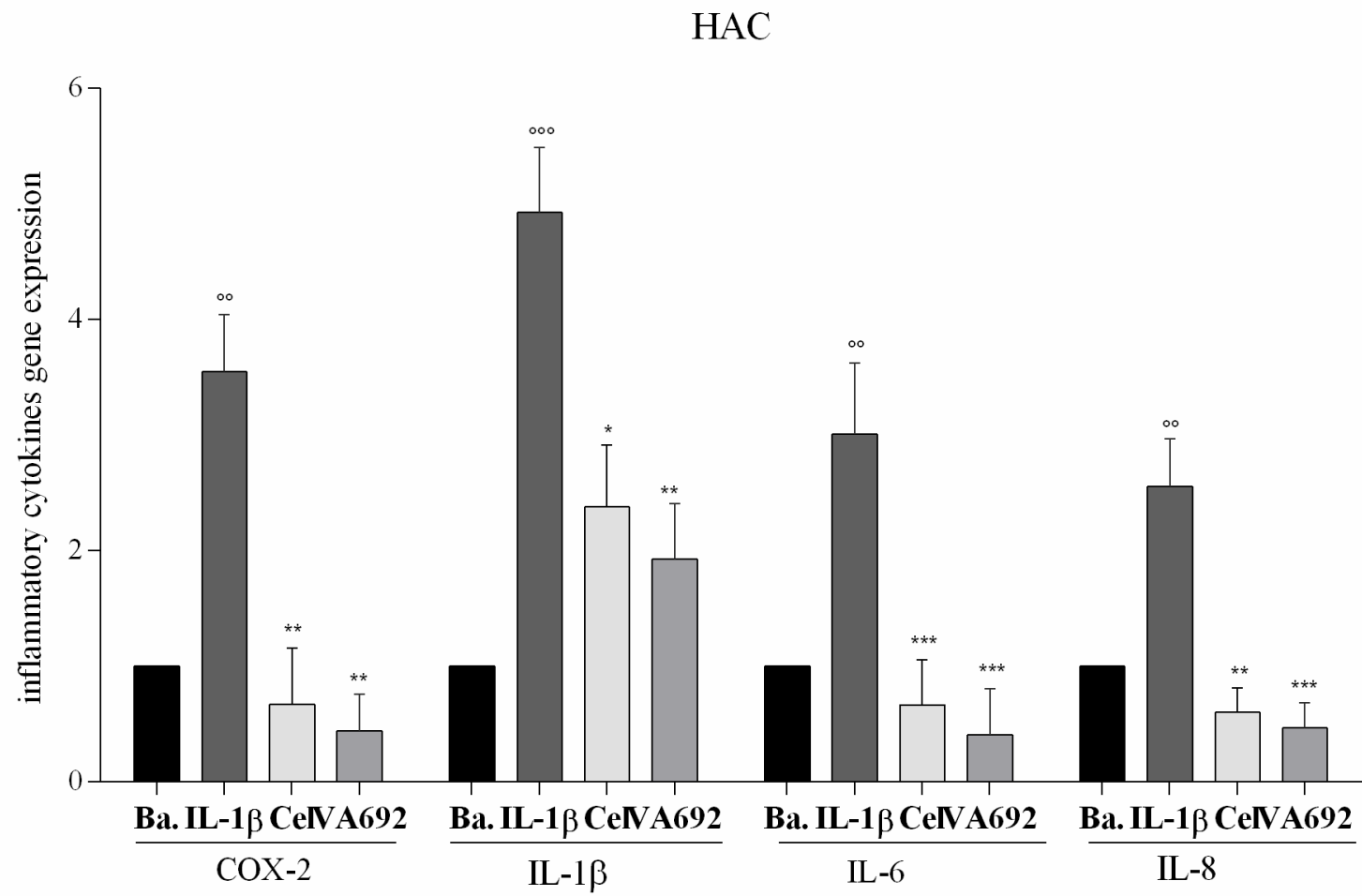




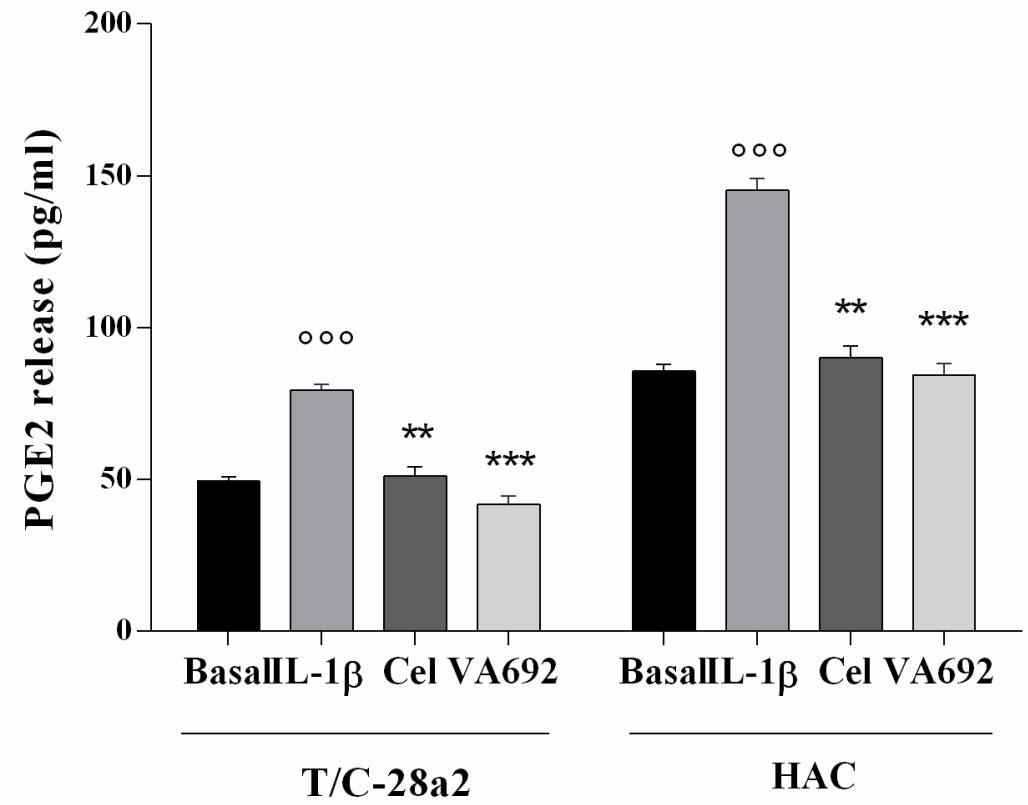

C 
Figure 3

Anion superoxide production

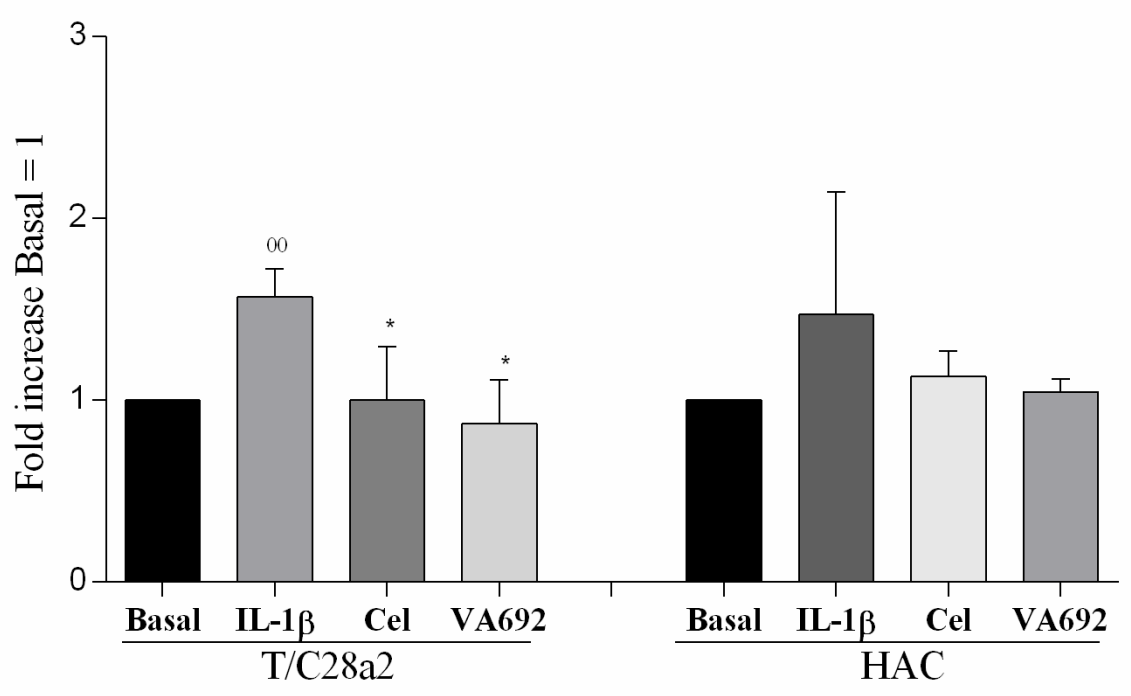

$\mathrm{T} / \mathrm{C} 28 \mathrm{a} 2$

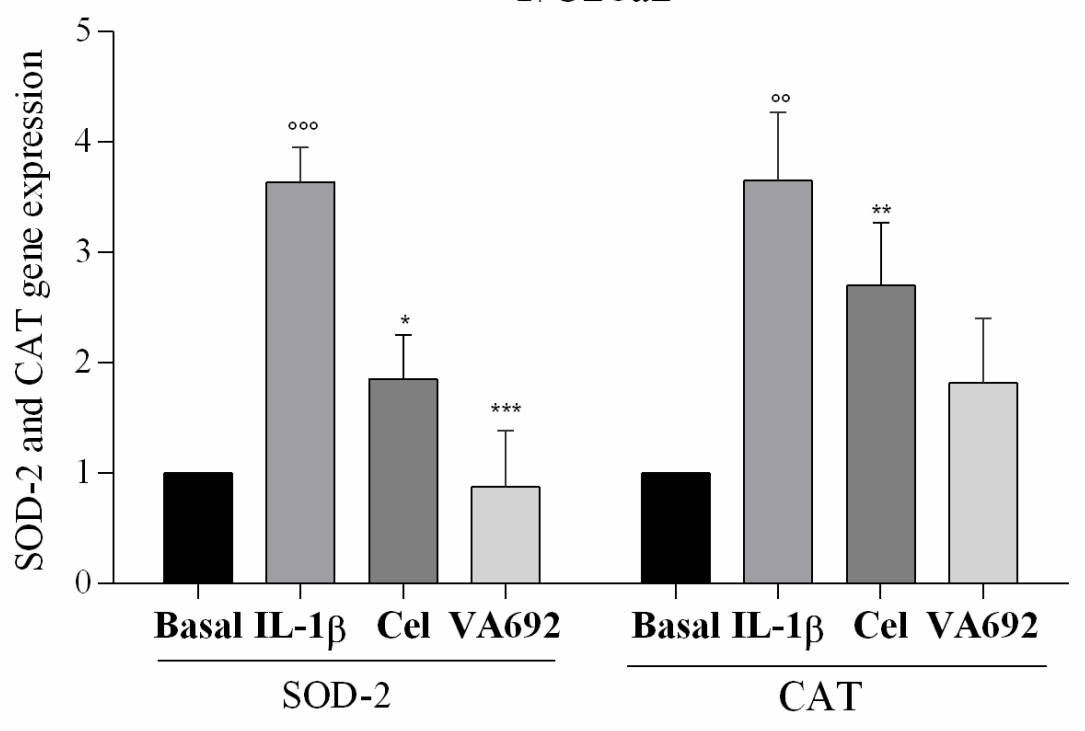

B 
HAC

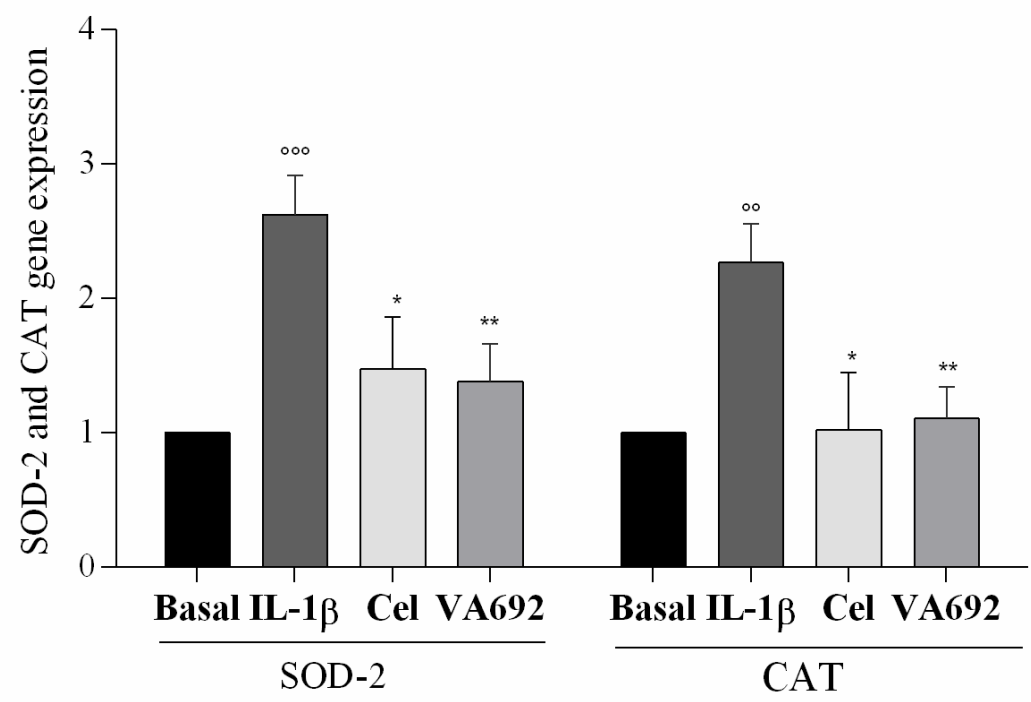

C
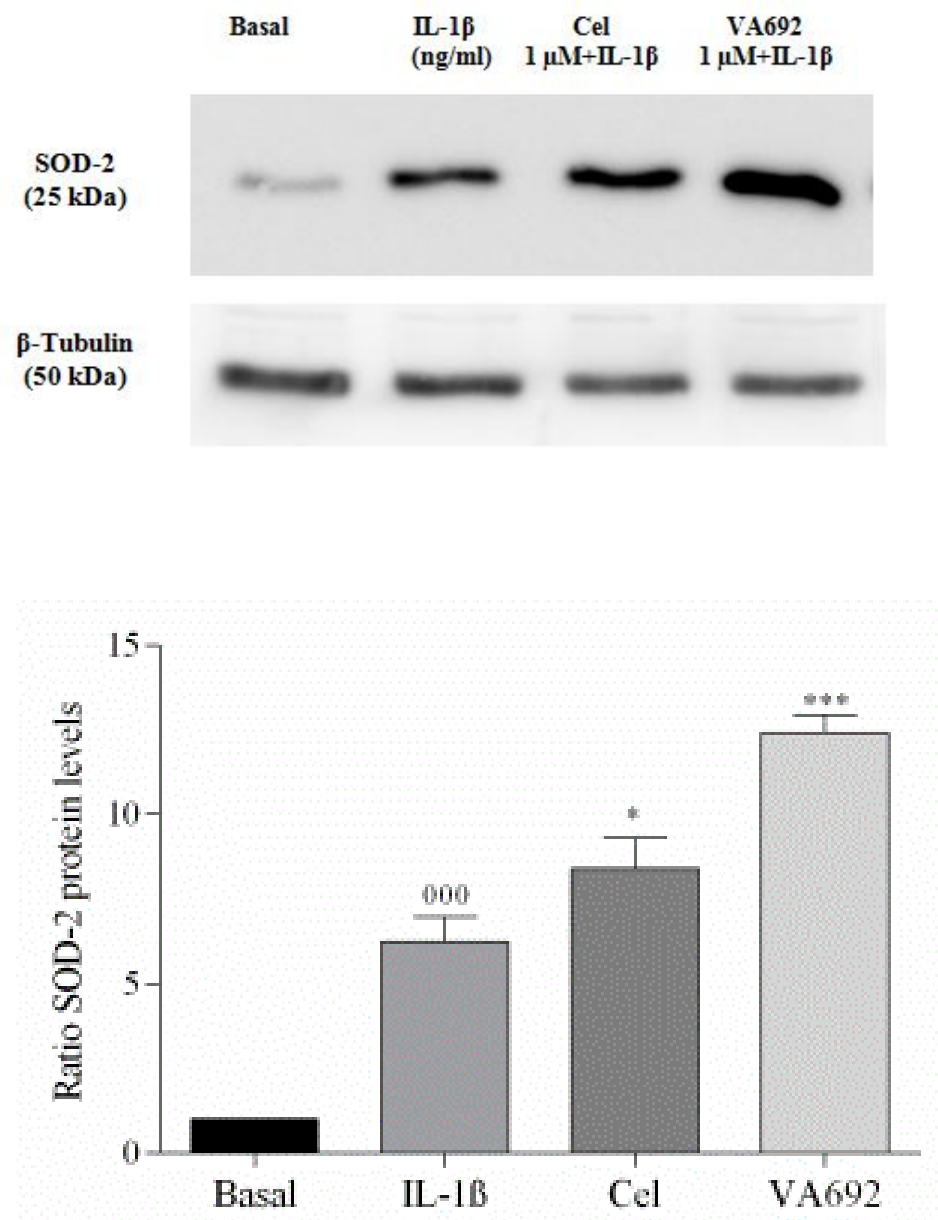


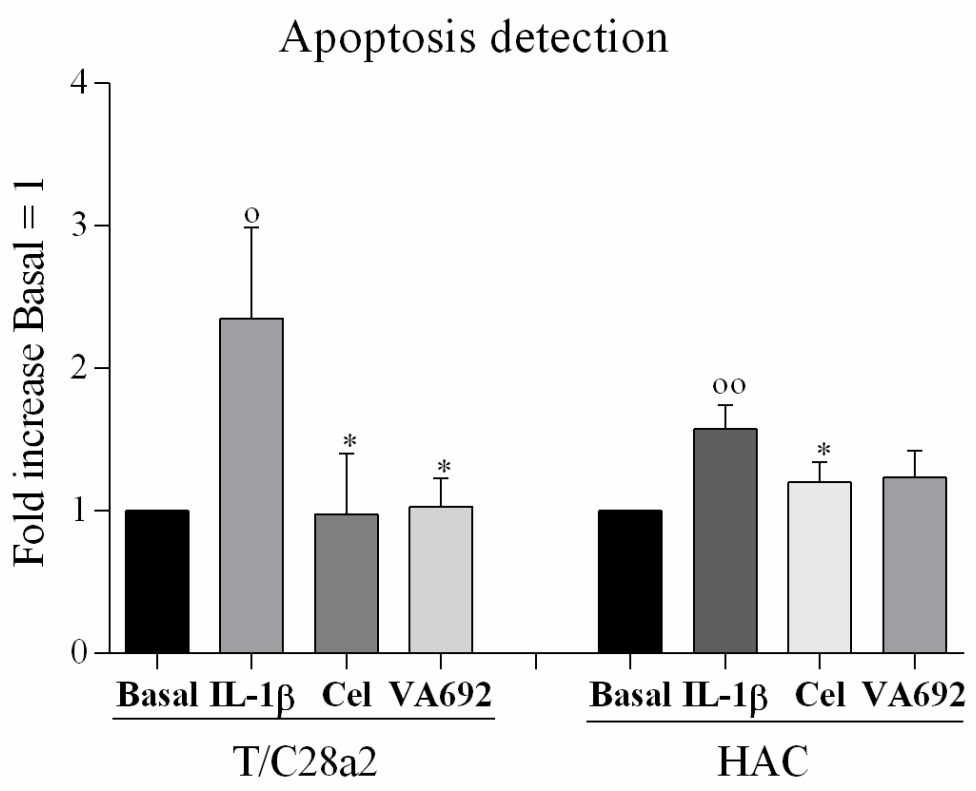

E

Figure 4 


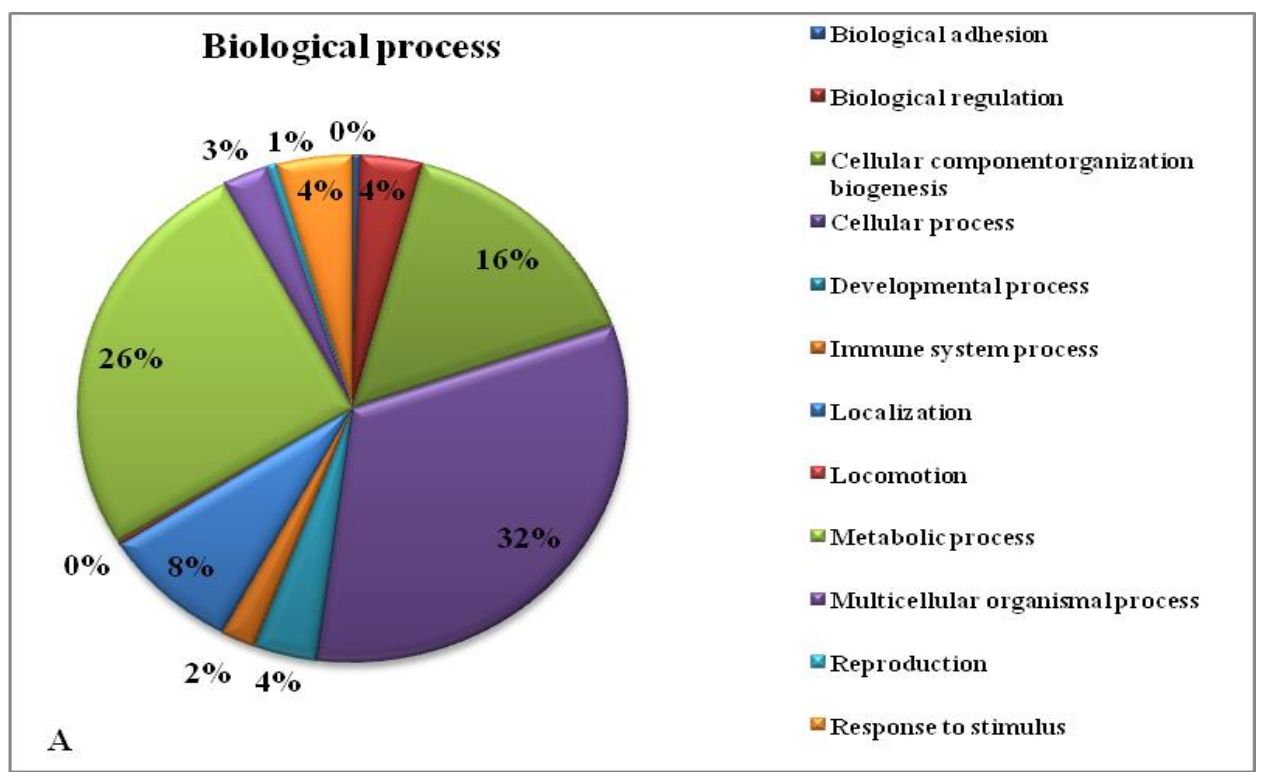
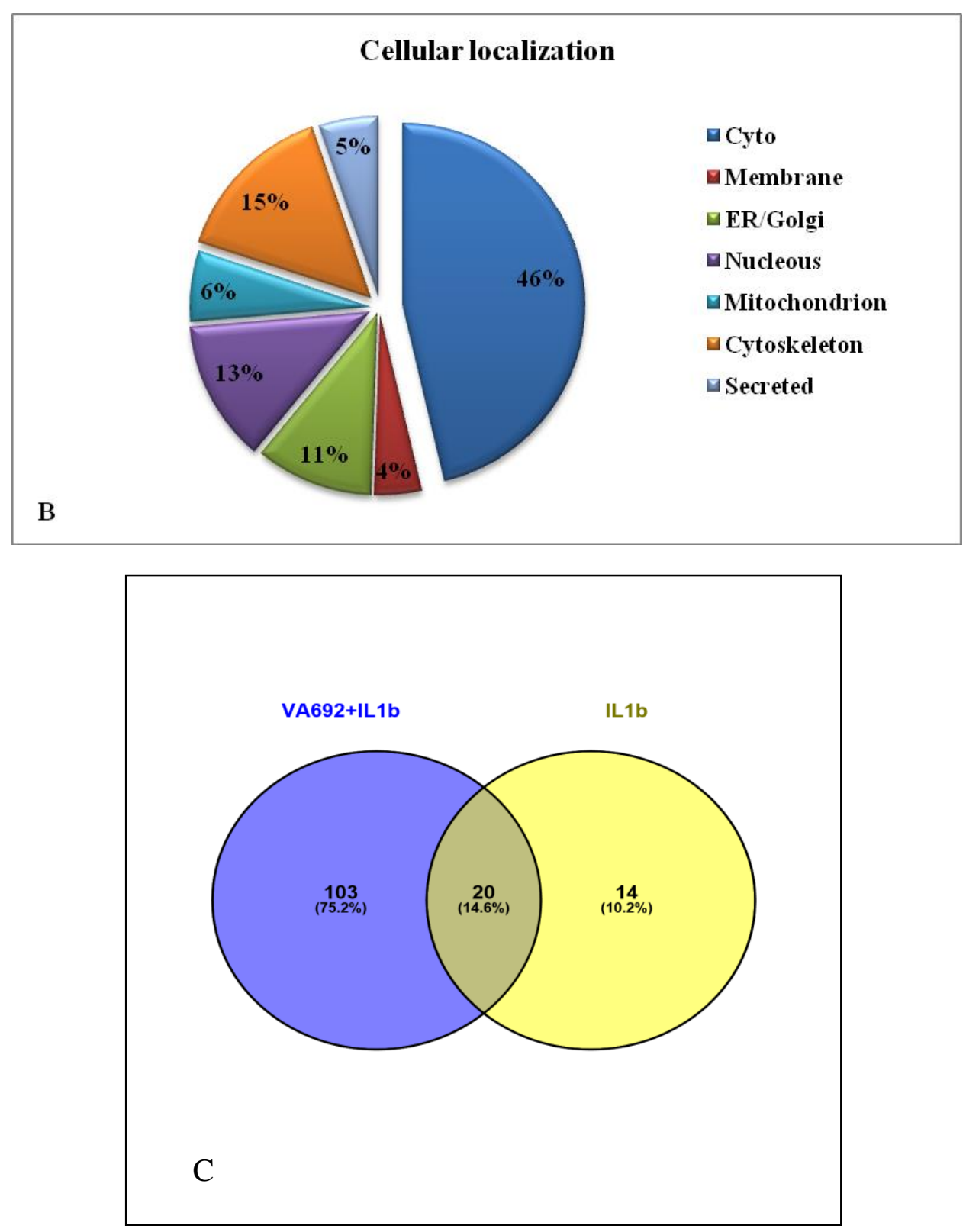
Figure 5

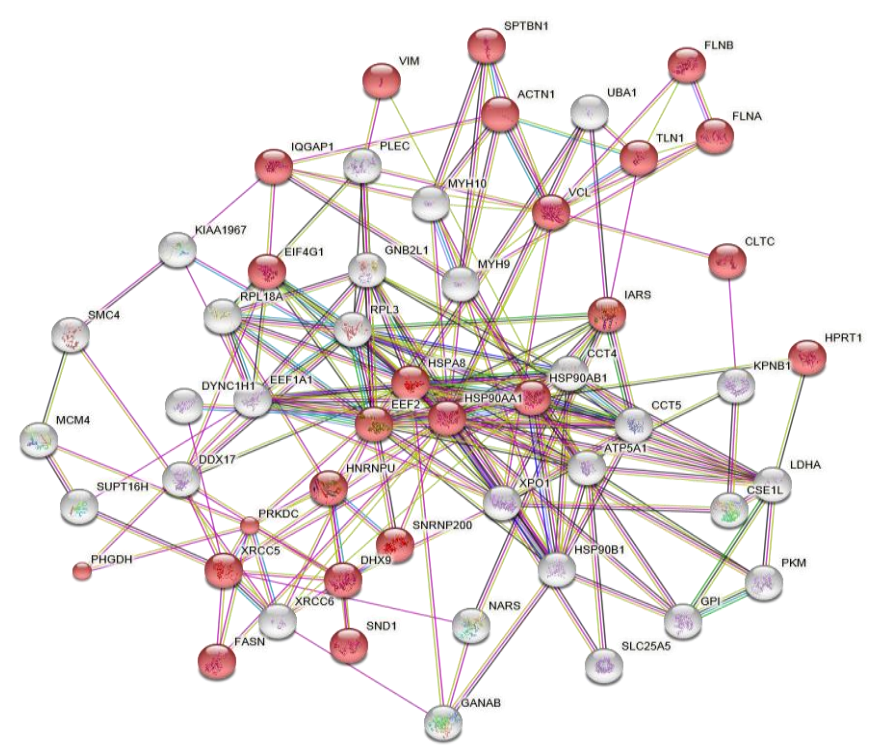

A

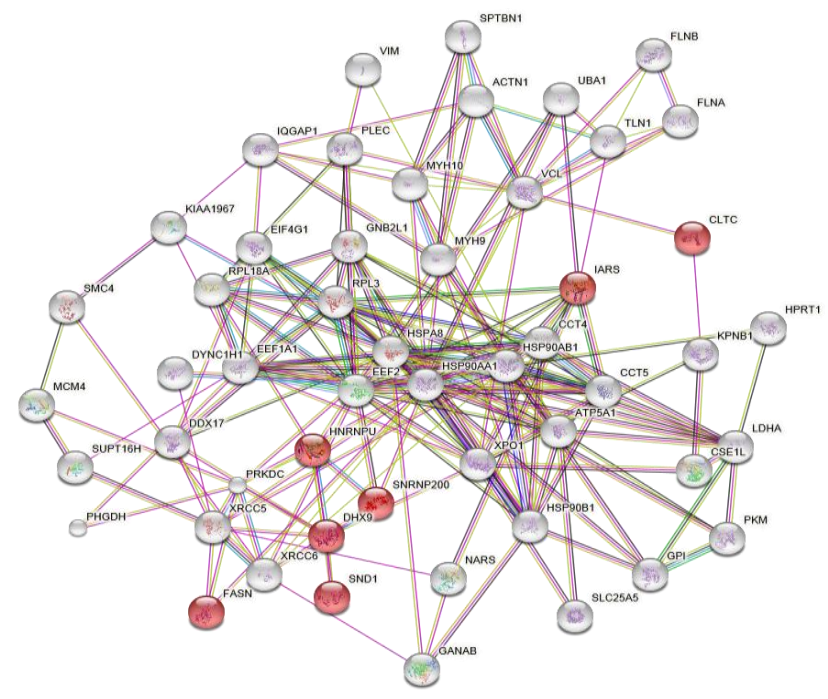

B 


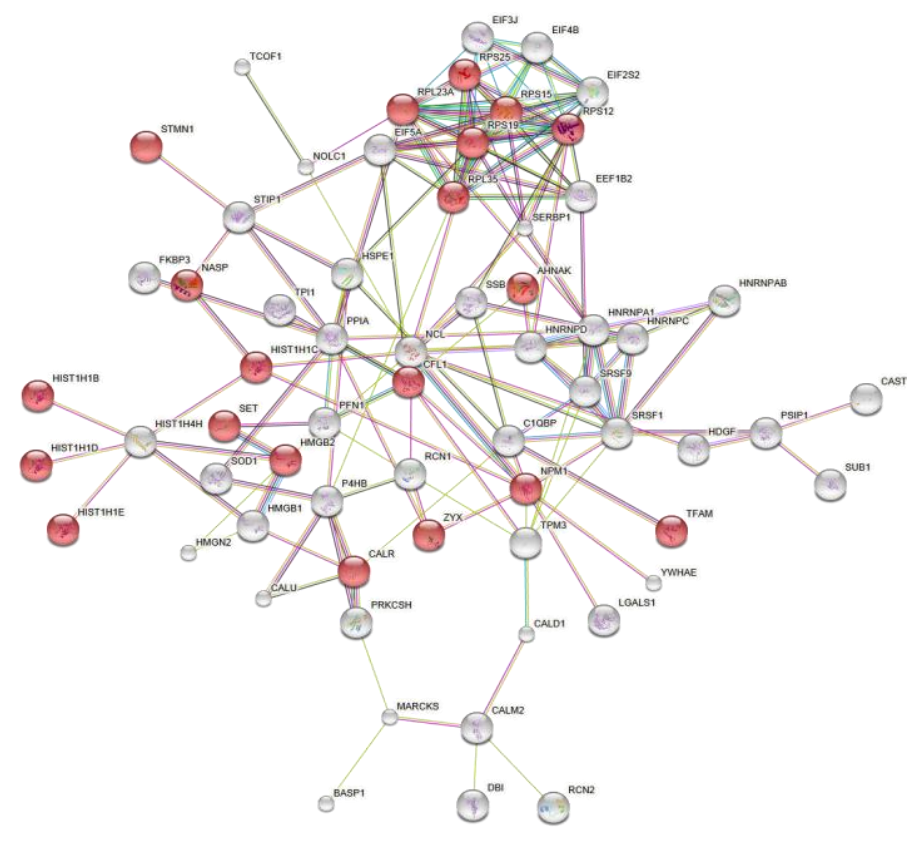

C

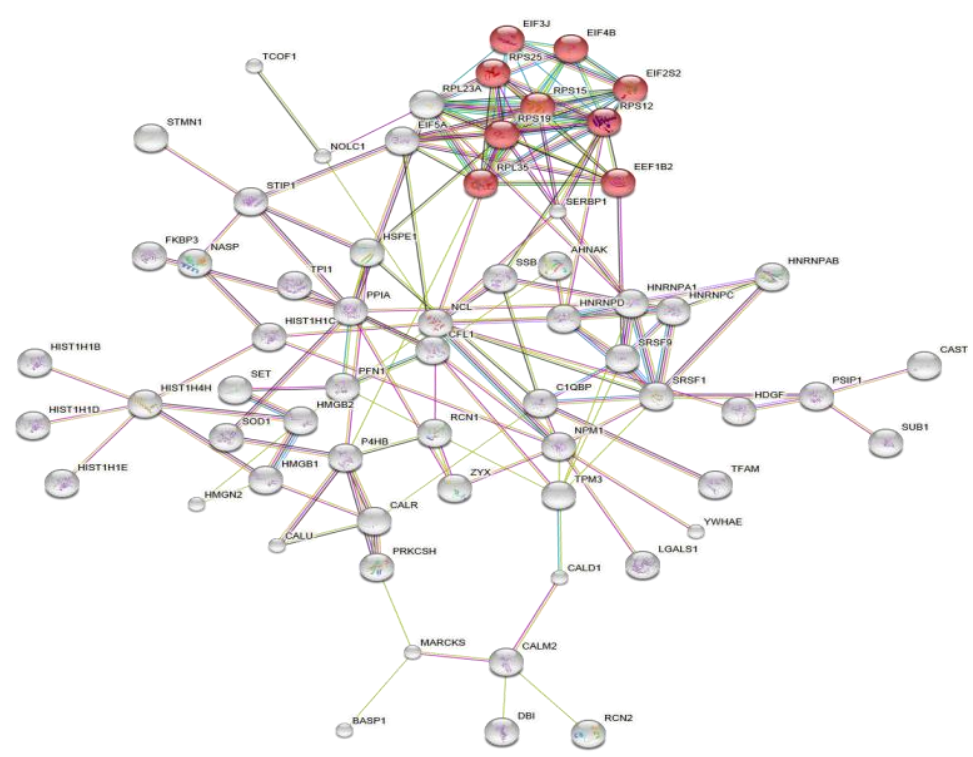

